LBNL-55718

\title{
Understanding the Cost of Power Interruptions to U.S. Electricity Consumers
}

\author{
Prepared for \\ Imre Gyuk \\ Energy Storage Program \\ Office of Electric Transmission and Distribution \\ U.S. Department of Energy \\ and \\ Sam Baldwin \\ Office of Planning, Budget, and Analysis \\ Assistant Secretary for Energy Efficiency and Renewable Energy \\ U.S. Department of Energy \\ by \\ Kristina Hamachi LaCommare and Joseph H. Eto \\ Ernest Orlando Lawrence Berkeley National Laboratory \\ 1 Cyclotron Road, MS 90-4000 \\ Berkeley CA 94720-8136
}

September 2004

The work described in this paper was funded by the Office of Electric Transmission and Distribution, Energy Storage Program and by the Assistant Secretary for Energy Efficiency and Renewable Energy, Office of Planning, Budget, and Analysis of the U.S. Department of Energy under Contract No. DE-AC03-76SF00098. 



\begin{abstract}
The massive electric power blackout in the northeastern United States and Canada on August 1415, 2003 resulted in the U.S. electricity system being called "antiquated" and catalyzed discussions about modernizing the grid. Industry sources suggested that investments of $\$ 50$ to $\$ 100$ billion would be needed. This report seeks to quantify an important piece of information that has been missing from these discussions: how much do power interruptions and fluctuations in power quality (power-quality events) cost U.S. electricity consumers? Accurately estimating this cost will help assess the potential benefits of investments in improving the reliability of the grid.
\end{abstract}

We develop a comprehensive end-use framework for assessing the cost to U.S. electricity consumers of power interruptions and power-quality events (referred to collectively as "reliability events").

The framework expresses these costs as a function of:

- Number of customers by type in a region;

- Frequency and type of reliability events experienced annually (including both power interruptions and power-quality events) by these customers;

- Cost of reliability events; and

- Vulnerability of customers to these events.

The framework is designed so that its cost estimate can be improved as additional data become available.

Using our framework, we estimate that the national cost of power interruptions is about $\$ 80$ billion annually, based on the best information available in the public domain. However, there are large gaps in and significant uncertainties about the information currently available. Notably, we were not able to develop an estimate of power-quality events. Sensitivity analysis of some of these uncertainties suggests that the total annual cost could range from less than $\$ 30$ billion to more than $\$ 130$ billion. Because of this large range and the enormous cost of the decisions that may be based on this estimate, we encourage policy makers, regulators, and industry to jointly undertake the comparatively modest-cost improvements needed in the information used to estimate the cost of reliability events. Specific areas for improvement include: coordinated, nationwide collection of updated information on the cost of reliability events; consistent definition and recording of the duration and frequency of reliability events, including powerquality events; and improved information on the costs of and efforts by consumers to reduce their vulnerability to reliability events. 



\section{Acknowledgments}

The work described in this paper was funded by the Office of Electric Transmission and Distribution, Energy Storage Program and by the Assistant Secretary of Energy for Energy Efficiency and Renewable Energy, Office of Planning, Budget, and Analysis of the U.S. Department of Energy under Contract No. DE-AC03-76SF00098. We acknowledge the guidance and direction provided by Imre Gyuk and Sam Baldwin, U.S. DOE. We also gratefully acknowledge comments on an early draft of this work provided by Anne-Marie Borberly-Bartis, John Boyes, Ali Chowdhury, Ken Friedman, Charles Goldman, Julie Gorte, Doug Hale, Scott Hassell, Pat Hoffman, Bill Howe, Joseph Iannucci, Leora Lawton, Chris Marnay, Philip Overholt, Marek Samotyj, Rich Scheer, Michael Sullivan, Jane Thornton, Kent Van Liere, and Mary Beth Zimmerman. 



\section{Table of Contents}

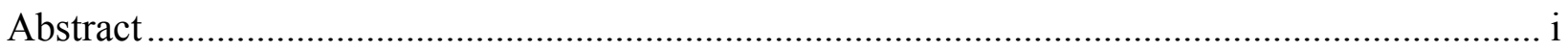

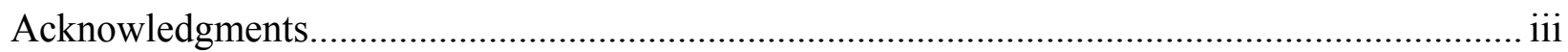

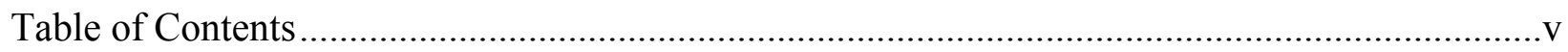

List of Figures and Tables................................................................................................... vii

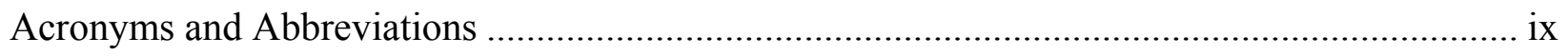

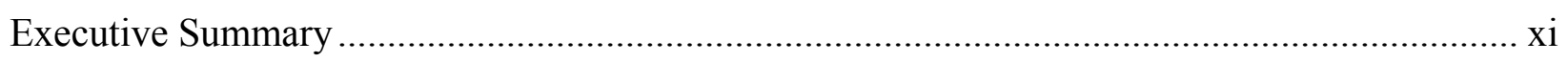

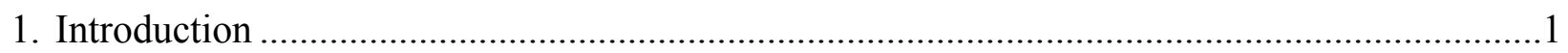

2. An End-Use Framework for Estimating the Economic Cost of Power Interruptions and Power

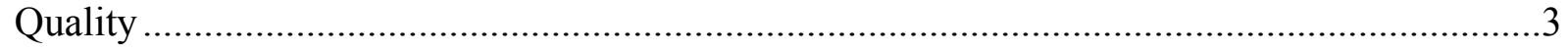

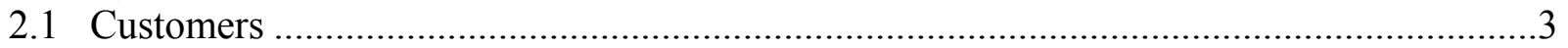

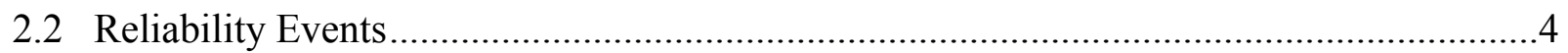

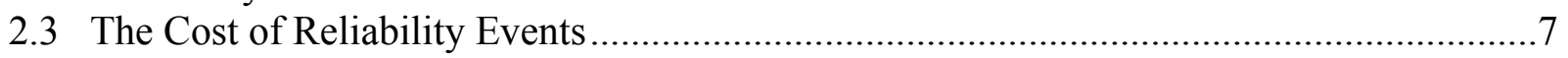

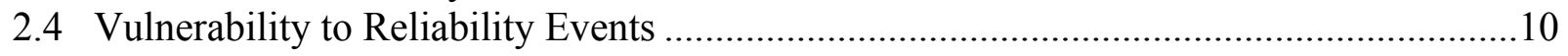

3. Assessing Recent Estimates of the Economic Cost of Reliability Events .................................11

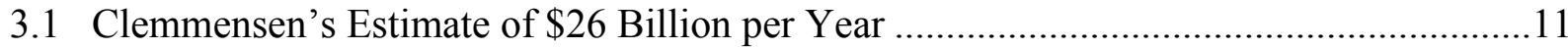

3.2 Swaminathan and Sen's Estimate of $\$ 150$ Billion per Year.............................................12

3.3 Primen's Estimate of \$119 Billion per Year....................................................................13

4. Deriving a New Estimate of the Economic Cost of Power Interruptions to U.S. Electricity

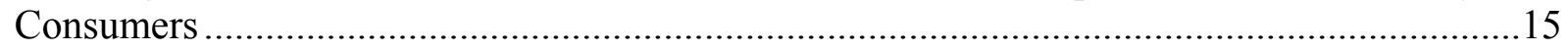

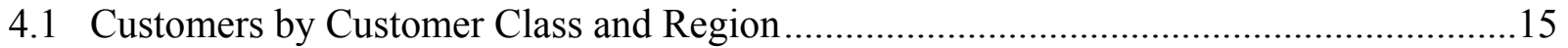

4.2 The Duration and Frequency of Reliability Events .........................................................17

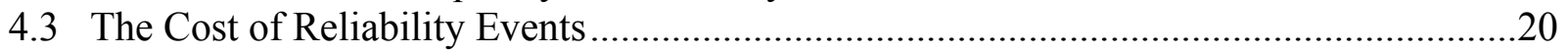

4.3.1 Accounting for Regional Variation in Reliability Event Costs ................................20

4.3.2 Accounting for Time of Day, Week, and Season When Reliability Events Occur ...24

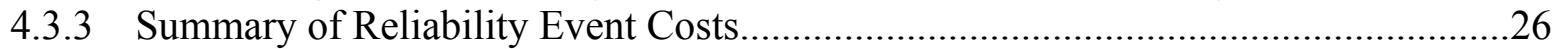

4.4 Vulnerability of Customers to Reliability Events .............................................................2.

4.5 LBNL Base-Case Estimate of the Economic Cost of Power Interruptions .......................26

5. Using Sensitivity Analysis to Explore the Uncertainty in the LBNL Estimate ..........................31

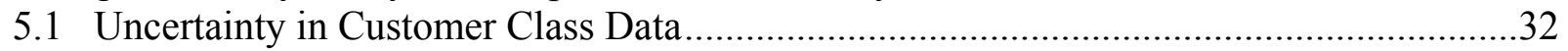

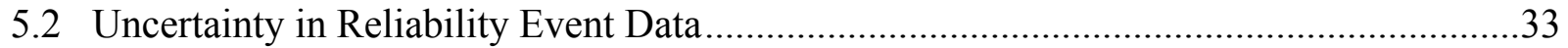

5.2.1 Year-to-Year Variation in Reliability Events ...........................................................34

5.2.2 Regional Variation in Reliability Events .......................................................................34

5.2.3 Differences by Customer Classes in Reliability Events .............................................36

5.3 Uncertainty in Reliability Event Costs ................................................................................36

5.3.1 Impact of Time when Interruptions Occur on Cost of Reliability Events ..................37 
5.3.2 Effect of Using Unadjusted Survey Information on Cost of Reliability Events........37

6. Summary, Conclusions, and Priorities for Improving Future Estimates................................41

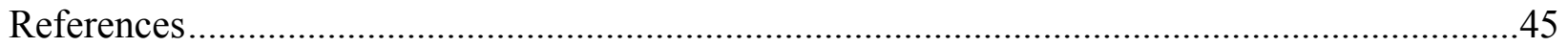

Appendix A. Listing of SAIDI, SAIFI, and MAIFI Data .................................................. 


\section{List of Figures and Tables}

Figure ES- 1. LBNL Base-Case Estimate of the Cost of Power Interruptions by Customer Class

xii

Figure ES- 2. LBNL Base-Case Estimate of the Cost of Power Interruptions by Type of

Interruption ......................................................................................................

Figure ES- 3. Summary of U.S. Cost of Power Interruption Sensitivity Cases.........................xiii

Figure 1. Voltage Deviation as a Function of Duration of Event ............................................ 8

Figure 2. Findings from a Recent Demonstration of a Power Quality Monitoring System in

California's Silicon Valley Displayed Against the CBEMA Curve. ................................ 9

Figure 3. Map of Modified Census Division Regions .......................................................... 17

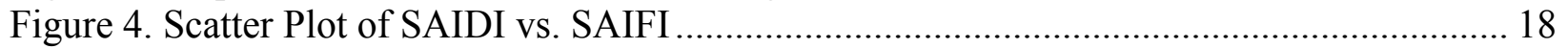

Figure 5. Scatter Plot of SAIFI vs. MAIFI ............................................................................... 19

Figure 6. Map Relating U.S. Manufacturing Regions to Census Divisions ............................... 21

Figure 7. LBNL Base-Case Estimate of the Cost of Power Interruptions by Customer Class..... 27

Figure 8. LBNL Base-Case Estimate of the Cost of Power Interruptions by Type of Interruption

Figure 9. LBNL Base-Case Estimate of the Cost of Power Interruptions by Region and Customer

Class with C\&I Population................................................................................... 28

Figure 10. Summary of U.S. Cost of Power Interruption Reliability Event Sensitivity Cases .... 33

Figure 11. Summary of U.S. Cost of Power Interruption Outage Cost Sensitivity Cases............ 37

Figure 12. Reliability Events that Could be Addressed by Energy Storage ............................... 39

Table ES- 1. Review of Assumptions Used to Develop LBNL Base-Case Estimate of the Cost of

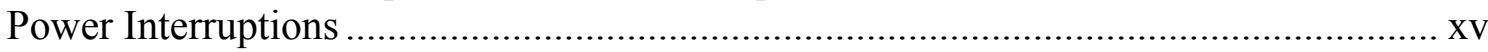

Table 1. Sources of Uncertainty in Estimating the Cost of Reliability Events............................ 4

Table 2. Summary of Primen Study Results .......................................................................... 14

Table 3. The Data Used to Develop a National Estimate of the Cost of Power Interruptions ..... 15

Table 4. Number of Customers by Region and Sector in 2001 ............................................... 16

Table 5. Summary of Trimmed Mean and Total Mean Reliability Event Data ........................ 18

Table 6. Summary of U.S. Reliability Event Estimates by External Studies ............................ 19

Table 7. Summary of Tobit Regression Parameters ................................................................. 23

Table 8. Distribution of Weekday and Weekend Days.......................................................... 25

Table 9. Tobit Regression Season, Time of Day, and Day Type Parameter Combinations ......... 25

Table 10. Tobit Regression Estimated Cost-per-Outage-per-Customer for the U.S. ${ }^{1}$................. 26

Table 11. Key Uncertainties in the Assumptions Used in the LBNL Base-Case Estimate of the

Cost of Power Interruptions ................................................................................ 31

Table 12. Regional Variation in Collected Reliability Event Data........................................... 35

Table 13. Tobit Regression Estimated Cost-per-Outage-per-Customer by Region ${ }^{1}$................... 35

Table 14. PRS Unsmoothed Cost-per-Outage-per-Customer Data ............................................ 38

Table 15. Benefits and Market Potential, Over Ten Years, for Energy Storage, used in California,

to Improve Electric Service Reliability ..................................................................... 40 



\section{Acronyms and Abbreviations}

$\begin{array}{ll}\text { CBECS } & \text { Commercial Buildings Energy Consumption Survey } \\ \text { C\&I } & \text { commercial and industrial } \\ \text { CPI } & \text { Consumer Price Index } \\ \text { DOE } & \text { U.S. Department of Energy } \\ \text { EIA } & \text { Energy Information Administration } \\ \text { EPRI } & \text { Electric Power Research Institute } \\ \text { hr } & \text { hour } \\ \text { LBNL } & \text { Lawrence Berkeley National Laboratory } \\ \text { MAIFI } & \text { Momentary Average Interruption Frequency Index } \\ \text { MECS } & \text { Manufacturing Energy Consumption Survey } \\ \text { min } & \text { minute } \\ \text { NAICS } & \text { North American Industry Classification System } \\ \text { NEMS } & \text { DOE/EIA's National Energy Modeling System } \\ \text { PRS } & \text { Population Research Systems } \\ \text { RECS } & \text { Residential Energy Consumption Survey } \\ \text { SAIDI } & \text { System Average Interruption Duration Index } \\ \text { SAIFI } & \text { System Average Interruption Frequency Index } \\ \text { sec } & \text { second } \\ \text { SIC } & \text { Standard Industrial Classification }\end{array}$





\section{Executive Summary}

The massive electricity blackout in the northeastern United States and Canada on August 14-15, 2003 rekindled public interest in the reliability of the electricity grid. Following the outage, the U.S. electricity system was called "antiquated" and likened to that of a third-world nation. Industry sources suggested that investments of $\$ 50$ to $\$ 100$ billion would be needed to modernize the grid. This report seeks to quantify an important piece of information that has been missing from these discussions: how much do power interruptions and power-quality events cost U.S. electricity consumers? Accurately estimating these costs will help to assess the potential benefits of investments in improving the reliability of the grid.

We develop a comprehensive end-use framework for assessing the cost to U.S. electricity consumers of power interruptions and power-quality events. This framework, which can be readily updated as additional data become available, expresses annual power-interruption and power-quality costs (referred to collectively as "reliability events") as a function of the:

- Number of customers by class and region;

- Duration and frequency of reliability events experienced annually (including both power interruptions and power-quality events) by customers;

- $\quad$ Cost of reliability events, by event type, customer class, and region; and

- Vulnerability of customers to reliability events. ${ }^{1}$

We use the framework to review previous estimates of the national cost of power interruptions and power quality, including those developed by the Electric Power Research Institute (EPRI) and the U.S. Department of Energy (DOE), which range from $\$ 26$ billion to $\$ 400$ billion annually. Our analysis shows that key assumptions underlying these early estimates reveal potentially significant biases; many of these biases cannot be fully understood until better information is collected than is currently available on the elements that contribute to the costs of reliability events.

Following our review of existing estimates, we use the best information currently available in the public domain to develop a new estimate of the national cost of power interruptions. We do not include power-quality events. Our base-case estimate of the national cost of power interruptions is approximately $\$ 80$ billion annually as shown in Figure ES-1, broken down by customer class. Table ES-1 summarizes the information used in developing our estimate.

\footnotetext{
1 The vulnerability of customers to reliability events is included because it is an important component of the cost of reliability events. However, because there are no reliable, current data on customer investments in reliability-enhancing technologies (e.g., back-up generation, batteries, power-conditioning equipment), this component is not currently incorporated in our estimates or sensitivity analyses.
} 


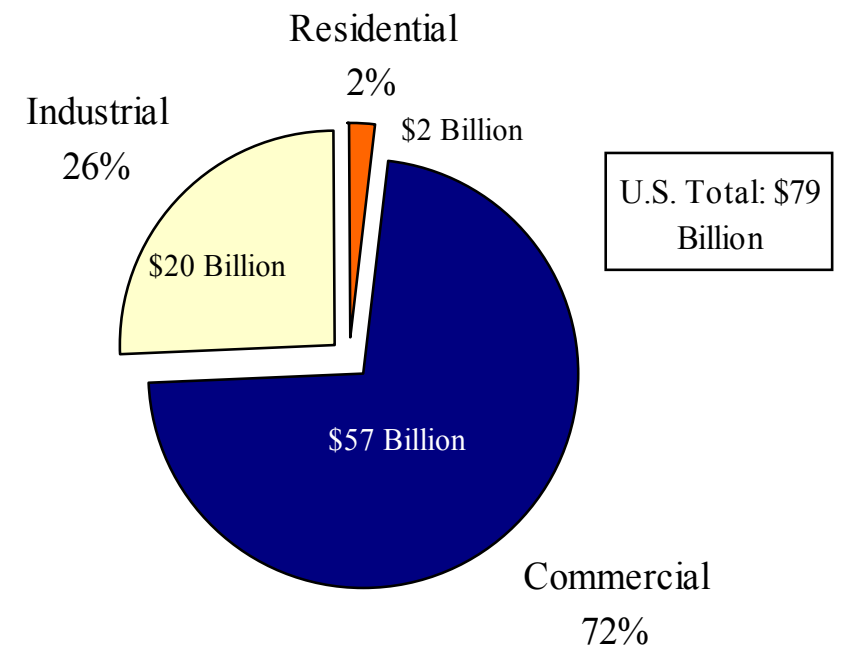

Figure ES- 1. LBNL Base-Case Estimate of the Cost of Power Interruptions by Customer Class

Our analysis shows that:

- The majority of outage costs are borne by the commercial and industrial sectors;

- As a result, although there are important variations in the composition of customers within each region, the total cost of reliability events by region tend to correlate roughly with the numbers of commercial and industrial customers in each region; and

- $\quad$ Costs tend to be driven by the frequency rather than the duration of reliability events

Related to this last finding, our work reveals the importance of short-term, momentary interruptions, which last 5 minutes or less. Figure ES-2 shows that (more frequent) momentary power interruptions have a stronger impact on the total cost of interruptions than (less frequent) sustained interruptions, which last 5 minutes or more.

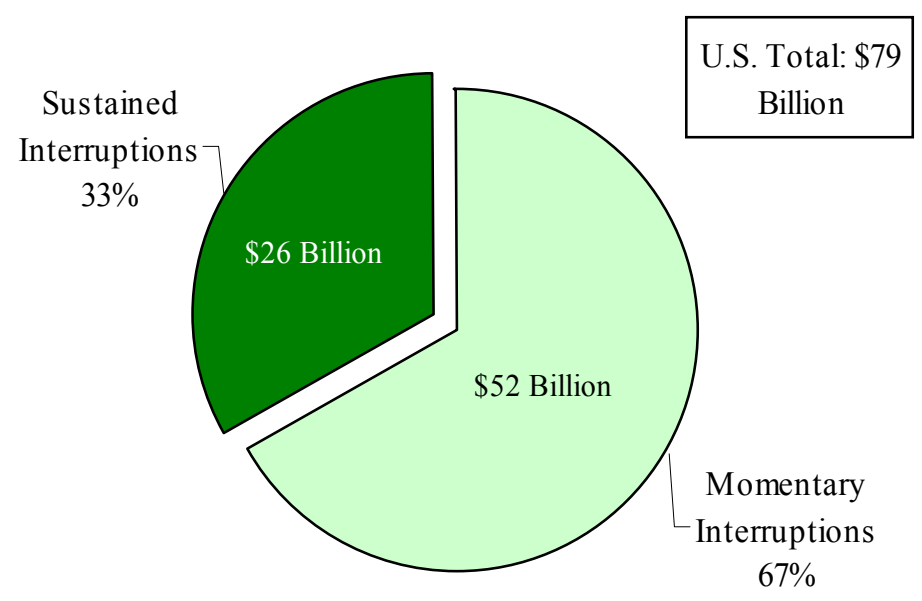

Figure ES- 2. LBNL Base-Case Estimate of the Cost of Power Interruptions by Type of Interruption 
This finding is consistent with the observation that the "down-time" associated with a power interruption can be as or more important than the duration of the interruption, itself.

Consistent with our review of prior estimates, we also find in developing our own estimate that there are significant gaps and uncertainties in the information currently available to support any estimate of the national cost of power interruptions. (Table ES-1 summarizes the uncertainties and their effects.)

To understand the effects of these uncertainties, we performed a sensitivity analysis of our base case in which we varied key parameters used in our calculation in order to quantify the impact of these variations on our results. Figure ES-3 shows the resulting total cost of power interruptions for each of the following variations:

- Assuming that the duration and frequency of reliability events varies by region, based on the limited region-specific data we collected;

- Assuming that the duration and frequency of reliability events is one standard deviation greater and less than the values used in our initial estimate, based on the total sample of data we collected;

- Assuming that all outages are valued based on the assumption that they occur on a summer weekday afternoon or summer weekend night; and

- Assuming that the commercial and industrial sectors experience a disproportionately lower duration and frequency of reliability events than the residential sector.

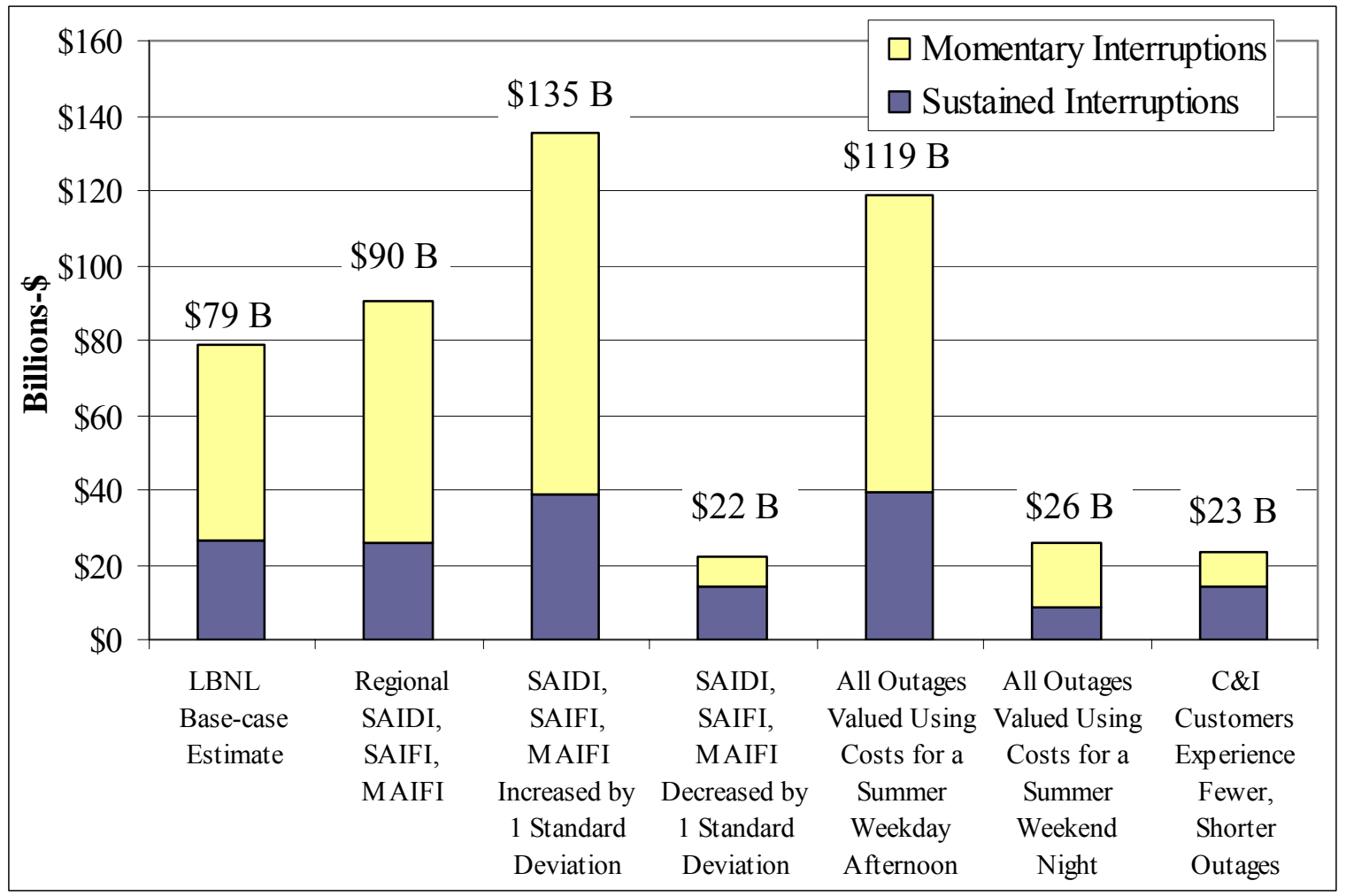

Figure ES- 3. Summary of U.S. Cost of Power Interruption Sensitivity Cases 
We find that the annual cost of power interruptions:

- Could be as low as \$22 billion or as high as \$135 billion when we consider a reasonable range in the annual duration and frequency of power interruptions, which addresses both gaps in the data for certain regions and possible year-to-year variations in reliability;

- $\quad$ Might be calculated to be as high as $\$ 119$ billion if all reliability events are (incorrectly) assumed, as is typical in many studies, to occur during summer weekday afternoons when power usage and costs are high; and

- Could be as low as $\$ 23$ billion when we take into consideration that larger commercial and industrial customers typically experience fewer and shorter interruptions than do residential and smaller commercial customers, which results from the design of many utility distribution systems.

In view of the large range of plausible estimates and the enormous cost of the private and public decisions that will be based on them, we encourage policy makers, regulators, and industry to work to jointly work to undertake the modest-cost activities that are needed to improve the information that is available on reliability events and their costs.

Specific areas for improvement include:

- Coordinated, nationwide collection of updated information on the cost of reliability events to customers;

- Consistent definition and tracking of the frequency, duration, timing, and number and type of customers affected by reliability events, including power-quality events; and

- Collection of information on efforts by customers to reduce their vulnerability to reliability events through investments in technology (such as back-up generators and energy storage) and other measures. 
Table ES- 1. Review of Assumptions Used to Develop LBNL Base-Case Estimate of the Cost of Power Interruptions

\begin{tabular}{|c|c|c|c|}
\hline & $\begin{array}{l}\text { Source of Information Used } \\
\text { in This Study }\end{array}$ & Uncertainties in These Sources of Information & $\begin{array}{c}\text { Assessment of the Impact } \\
\text { of These Uncertainties }\end{array}$ \\
\hline Customers & $\begin{array}{l}\text { Customer classes (residential, } \\
\text { commercial, and industrial) } \\
\text { and populations as defined } \\
\text { and estimated by the U.S. } \\
\text { Energy Information } \\
\text { Administration (EIA) for } 10 \\
\text { regions of the U.S. (with } \\
\text { California treated separately). }\end{array}$ & $\begin{array}{l}\text { Customer classes defined by EIA (residential, } \\
\text { commercial, industrial) are not consistent with } \\
\text { customer revenue classes used by utilities } \\
\text { (residential, small and medium commercial and } \\
\text { industrial (C\&I), and large C\&I) }\end{array}$ & No clear direction in bias \\
\hline $\begin{array}{l}\text { Duration } \\
\text { and } \\
\text { Frequency of } \\
\text { Reliability } \\
\text { Events }\end{array}$ & $\begin{array}{l}\text { Trimmed means for three } \\
\text { major industry reliability } \\
\text { indices collected from an on- } \\
\text { line search of utility and state } \\
\text { PUC websites. } \\
\text { SAIDI }{ }^{1} \\
\text { Mean }=106 \text { min. } \\
\text { Std. Dev. }=54 \text { min. } \\
\text { N }=162 \\
\text { SAIFI } \\
\text { Mean }=1.2 \\
\text { Std. Dev. }=0.5 \\
\text { N }=162 \\
\text { MAIFI }{ }^{3} \\
\text { Mean }=4.3 \\
\text { Std. Dev. }=3.6 \\
\text { N }=52\end{array}$ & $\begin{array}{l}\text { SAIDI, SAIFI, and MAIFI are not collected } \\
\text { consistently and are often collected using } \\
\text { inconsistent definitions. } \\
\text { SAIDI and SAIFI data sometimes exclude major } \\
\text { events (such as those caused by large storms). } \\
\text { SAIFI data sometimes include MAIFI data. } \\
\text { SAIDI, SAIFI, and MAIFI exhibit year-to-year } \\
\text { variability. } \\
\text { SAIDI, SAIFI, and MAIFI data are typically } \\
\text { reported for an entire population, not by customer } \\
\text { class. } \\
\text { SAIDI, SAIFI, and MAIFI data difficult to find for } \\
\text { all regions. } \\
\text { SAIDI, SAIFI, and MAIFI do not distinguish the } \\
\text { time when interruptions occur. }\end{array}$ & $\begin{array}{l}\text { Likely bias is to } \\
\text { underestimate costs } \\
\text { Likely bias is to } \\
\text { overestimate costs } \\
\text { No clear direction in bias } \\
\text { Likely bias is to } \\
\text { overestimate costs (larger } \\
\text { customers typically } \\
\text { experience greater } \\
\text { reliability) } \\
\text { No clear direction in bias } \\
\text { No clear direction in bias }\end{array}$ \\
\hline
\end{tabular}




\begin{tabular}{|c|c|c|c|}
\hline & & $\begin{array}{l}\text { Information on power-quality events was not } \\
\text { included in this analysis because information on } \\
\text { power-quality events suffers from all of the above } \\
\text { limitations to an even greater degree than SAIDI, } \\
\text { SAIFI, and MAIFI. }\end{array}$ & $\begin{array}{l}\text { Likely bias is to } \\
\text { underestimate costs }\end{array}$ \\
\hline $\begin{array}{l}\text { Cost of } \\
\text { Reliability } \\
\text { Events }\end{array}$ & $\begin{array}{l}\text { Customer damage functions } \\
\text { for three customer revenue } \\
\text { classes (residential, small and } \\
\text { medium C\&I, and large C\&I) } \\
\text { were developed through a } \\
\text { separate national study of } \\
\text { utility outage-cost surveys } \\
\text { conducted by Population } \\
\text { Research Systems and } \\
\text { Lawrence Berkeley National } \\
\text { Laboratory (2003). In total, } \\
\text { more than } 60,000 \text { survey } \\
\text { responses from } 24 \text { past utility } \\
\text { studies were combined to } \\
\text { estimate customer damage } \\
\text { functions. }\end{array}$ & $\begin{array}{l}\text { Customer damage functions were estimated by } \\
\text { consolidating a large number of independent utility } \\
\text { outage-cost surveys. Although survey methods were } \\
\text { similar, they were not identical. } \\
\text { Changes in customer costs since the time of the } \\
\text { original surveys have not been examined. } \\
\text { Utility surveys do not capture infrastructure costs } \\
\text { associated with widespread major outages (e.g., the } \\
\text { Northeast blackout on August } 14-15,2003) \text {. }\end{array}$ & $\begin{array}{l}\text { No clear direction in bias } \\
\text { No clear direction in bias } \\
\text { Slight bias toward } \\
\text { underestimating costs } \\
\text { (major outages are rare } \\
\text { events.) }\end{array}$ \\
\hline $\begin{array}{l}\text { Vulnerability } \\
\text { to Reliability } \\
\text { Events }\end{array}$ & $\begin{array}{l}\text { Not used in this study because } \\
\text { of the absence of reliable } \\
\text { information on customer } \\
\text { investments in reliability- } \\
\text { enhancing technologies (e.g., } \\
\text { back-up generators and energy } \\
\text { storage) and other measures. }\end{array}$ & $\begin{array}{l}\text { Comprehensive information on customer } \\
\text { investments in reliability enhancing technologies } \\
\text { (such as back-up generators and energy storage) is } \\
\text { not available. }\end{array}$ & $\begin{array}{l}\text { Likely bias is to } \\
\text { overestimate costs. }\end{array}$ \\
\hline
\end{tabular}

\footnotetext{
System Average Interruption Duration Index

${ }^{2}$ System Average Interruption Frequency Index

${ }^{3}$ Momentary Average Interruption Frequency Index

${ }^{4}$ Customer damage functions express the cost of outage as a function of outage duration, season, time of day, annual electricity use, and (depending on the customer class) household income or number of employees.
} 


\section{Introduction}

The massive blackout in the northeastern United States and Canada on August 14-15, 2003 rekindled public interest in the reliability of the electricity grid. Following the blackout, the U.S. electricity system was called "antiquated" and likened to that of a third-world nation. Industry sources suggested that investments of $\$ 50$ to $\$ 100$ billion would be needed to modernize the grid (Fialka 2003; Schieffer 2003). This report seeks to quantify an important piece of information that has been missing from these discussions: how much do power interruptions and fluctuations in power quality (power-quality events) cost U.S. electricity consumers? Accurately estimating this cost will help assess the potential benefits of investments in improving the reliability of the grid.

From a customer's perspective, electricity reliability problems come in a variety of forms. Interruptions or outages during which voltage drops to near zero for periods of time ranging from a few seconds to several hours are the most visible problems and affect the widest range of electricity-consuming equipment. Less apparent are smaller voltage deviations, either above or below nominal voltage, which influence the operation of only some types of equipment depending on the magnitude and duration of the variations. These smaller deviations are aspects of power quality. ${ }^{2}$ It is important to consider both outages and power quality problems because from a customer's perspective both can affect the cost of unreliable electricity.

During the past decade, there have been several efforts to assess the national cost of power interruptions and power quality. During the 1990s, the Electric Power Research Institute (EPRI) estimated the national cost of $\$ 26$ billion per year based on a figure that had been presented at a power-quality conference (Electric Power Research Institute 1993). Later, EPRI extrapolated from this figure and began reporting power-interruption costs of $\$ 50$ billion per year (Douglas 2000). During the same period, a U.S. Department of Energy (DOE) study offered cost of reliability estimates ranging from $\$ 150$ to $\$ 400$ billion per year, based on an extrapolation from a single utility value-of-service study (Swaminathan and Sen 1998). Finally and most recently, EPRI prepared a new set of cost of power interruption and power quality estimates ranging from $\$ 119$ billion to $\$ 188$ billion per year; $\$ 119$ billion per year is the figure most often quoted from that study (Primen 2001).

Little has been done to systematically analyze the accuracy of these estimates. This paper presents a framework for assessing the strengths and weaknesses of past estimates and characterizes the uncertainties inherent in past and future estimates of the economic cost of power interruptions and power quality. We illustrate the use of this framework by drawing on existing data from a variety of sources to develop a new estimate of the total economic cost to U.S. electricity consumers, not including power quality. We examine uncertainties and gaps in the information used to develop this estimate to define a range of plausible estimates that might be expected from future calculations. We also explore issues that may have introduced bias into

\footnotetext{
2 Power quality refers to the degree to which power characteristics align with the ideal: $120-\mathrm{V}$ or $480-\mathrm{V}$ (in the U.S.), 60-Hz., sinusoidal voltage and current waveform, with current and voltage in phase. Power quality problems therefore encompass not only variations in voltage magnitude but also a host of other, more subtle deviations from the ideal. Harmonics are one example. Harmonics are integer multiples of the fundamental frequency that are imposed on the fundamental frequency and can affect certain types of equipment, such as adjustable-speed drives.
} 
prior estimates. These examples allow us to pinpoint key sources of uncertainty inherent in any estimate of these costs. Based on the uncertainties we identify, we prioritize future data collection activities whose results can be used to refine estimates of these costs.

The paper is organized into five sections following this introduction:

- Section 2 describes the basic framework for estimating the cost of power interruptions and power quality.

- Section 3 uses the framework to evaluate the three published estimates described above.

- Section 4 uses publicly available data from a variety of sources to create an independent estimate of the cost of power interruptions to U.S. electricity customers (not including power quality).

- Section 5 uses sensitivity analysis to explore the significance of the uncertainties in the initial estimate developed in Section 4.

- Section 6 summarizes our findings and conclusions and offers recommendations for improving future estimates.

\section{Energy Storage and Electricity Reliability}

This report was sponsored by the United States Department of Energy's (DOE) Office of Electricity Transmission and Distribution, in part, to quantify the possible financial benefits if electric energy storage (storage) is used to improve electric service reliability.

Storage can attenuate most manifestations of poor power quality and in some cases can provide direct electrical "support" to the grid (transmission and distribution systems). For generation and transmission systems storage can be an important tool to maintain system stability. At the local/electricity distribution level, storage can absorb, filter out or otherwise compensate for many types of poor power quality and can provide power during longer duration interruptions lasting for a few minutes to a few hours.

Storage may be a superior solution for reliability enhancement if conventional utility options to improve reliability are limited or constrained and/or for locations where noise, air emissions, zoning, or fuel-related issues limit use of generation-based solutions. Furthermore, unlike generation-based solutions most storage (system) types respond instantaneously to power quality events and to outages. 


\section{An End-Use Framework for Estimating the Economic Cost of Power Interruptions and Power Quality}

This section describes an end-use framework for estimating the economic costs of power interruptions and power quality to U.S. electricity consumers. The framework relies on a simple mathematical expression that determines the economic cost of power interruptions and power quality as follows:

Cost of Power Interruptions and Power Quality $=\sum_{i=1}^{m} \sum_{j=1}^{n} \sum_{k=1}^{p} N_{i, j} \times F_{i, j, k} \times C_{i, j, k} \times V_{i, j, k}$ where,

$N=$ number of electricity customers, by customer class for each region

$F=$ the frequency of reliability events by type of event experienced annually by customers by customer class for each region

$C=$ the cost per event by type of reliability event per customer by customer class for each region (2002-CPI-weighted dollars/event)

$V=$ the vulnerability of customers to each type of reliability event by customer class for each region (a fraction between 0 and 1 )

$m=$ the number of customers in each customer class

$n=$ the number of regions

$p=$ the type of reliability event

$i, j, k=$ indices for customer class, region, and type of reliability event, respectively

The simplicity of this formula belies the complexities involved in estimating the value of each of the four variables in the equation. The remainder of this section briefly summarizes some of the issues that can arise in developing the information needed to use this framework to estimate the cost of power interruptions and power quality. Table 1 summarizes some of the uncertainties associated with defining and gathering accurate data about each of the variables used for the quantification of the cost of power interruptions and power quality to U.S. electricity customers.

\subsection{Customers}

The number of customers considered when estimating the cost of power interruptions or power quality will have a significant impact on the accuracy of the estimate. Significant uncertainty can result from differences in how customers are defined. Customer definitions can include any one of the following: a single electricity account with one (or more) meters, such as a single-family detached residence; a single site/facility with multiple accounts, each possibly consisting of multiple meters, such as an apartment building; or multiple premises under common ownership, each with one or more accounts/meters, such as a chain of retail establishments. 
Table 1. Sources of Uncertainty in Estimating the Cost of Reliability Events

\begin{tabular}{|c|c|}
\hline Variable & Sources of Uncertainty \\
\hline Customers & $\begin{array}{l}\text { Customers and customer classes are not defined } \\
\text { consistently }\end{array}$ \\
\hline Reliability Events & $\begin{array}{l}\text { All reliability events are not always counted: } \\
\text { - Are power quality events and momentary } \\
\text { interruptions included? } \\
\text { - Are outages from major natural events included? } \\
\text { Aggregate or system level reliability measures do not } \\
\text { describe the reliability experienced by customers on } \\
\text { different classes of service or served by different } \\
\text { distribution system designs. } \\
\text { Aggregate of system level reliability measures suppress } \\
\text { the geographic and temporal distribution of reliability } \\
\text { events among the affected population of customers. }\end{array}$ \\
\hline Cost of Reliability Events & $\begin{array}{l}\text { Some costs may not be counted accurately or may not be } \\
\text { counted at all: } \\
\text { - How accurate are estimates of customers" } \\
\text { "willingness to pay" for unquantifiable } \\
\text { "inconvenience" factors associated with outages? } \\
\text { - Are business losses accurately counted so that only } \\
\text { net losses (i.e., excluding offset costs) are included? } \\
\text { - How do we account for societal/infrastructure costs, } \\
\text { e.g. costs associated with emergency response due to } \\
\text { a widespread outage? }\end{array}$ \\
\hline $\begin{array}{l}\text { Vulnerability to Reliability } \\
\text { Events }\end{array}$ & $\begin{array}{l}\text { Customer investments in technologies or measures to } \\
\text { reduce their exposure to reliability events are not } \\
\text { collected routinely. }\end{array}$ \\
\hline
\end{tabular}

Customer sectors are also not defined consistently. As we explain in detail in Section 5.1, it is difficult to reconcile data from sources that use different customer classification systems. For example, customers can be classified according to revenue accounts ("small and medium light and power" and "large light and power") or according to end-use forecasting categories (or market segments) made up of groupings of North American Industry Classification System (NAICS) codes. (Energy Information Administration 1990).

\subsection{Reliability Events}

Assessment of reliability involves looking at electromagnetic deviations from the ideal service that the U.S. electricity distribution system is designed to provide: a pure 60 -cycle per second alternating current at a designated voltage (120 volts for residential customers or 480 volts for many commercial or industrial customers). Any deviation from this standard that causes customers' equipment to fail or malfunction can be considered a reliability 'event.' Power interruptions (sometimes called outages or blackouts), which occur when voltage falls to zero for 
more than a few seconds, are the reliability problem with which most individuals have the greatest direct experience and are the key phenomena represented in utility reliability statistics.

While many utilities maintain detailed records of customer outage experience in their outage management systems, these data are usually reported in summary in the form of reliability event indices (Kueck et al. 2004). The System Average Interruption Duration Index (SAIDI) and System Average Interruption Frequency Index (SAIFI) describe the duration and frequency, respectively, of sustained interruptions experienced by customers of a utility in one year (IEEE 1995; IEEE 1999). According to IEEE, a "sustained interruption" is defined as any interruption that lasts at least five minutes and is not classified as a momentary interruption.

The SAIDI index represents the average length of time customers are interrupted and is defined as,

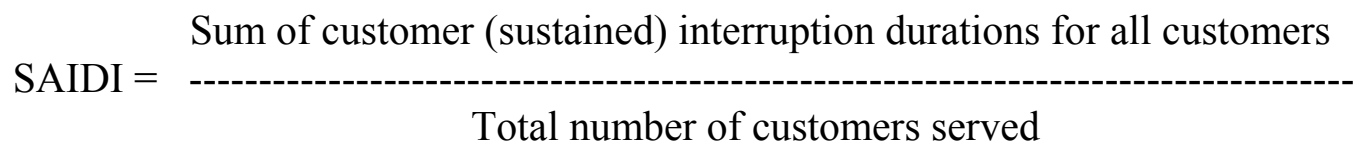

The SAIFI index represents the total number of customer interruptions per customer for a specified electric supply system and is defined as,

Total number of customer (sustained) interruptions for all customers

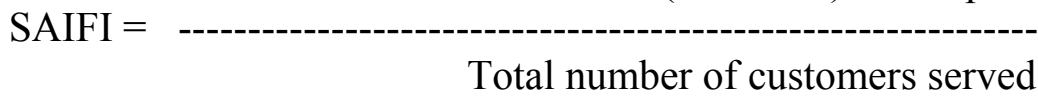

There are other reliability indices, too, but SAIDI and SAIFI measurements are the two indices most commonly used by utilities and industry experts to report on the quality of service based on duration and frequency of electricity outages ${ }^{3}$. In this paper, SAIDI and SAIFI data are used to quantify the magnitude of duration and frequency of sustained electricity interruption events for a typical year.

Although SAIDI and SAIFI are useful for assessing the costs and effects of power interruptions, these data are often either not collected by utilities or are collected inconsistently (Warren et al. 2003). That is, the information collected by utilities, if it is collected (and reported) at all, varies in the details or variables that are recorded. Thus, a major source of uncertainty is that many reliability events that have measurable cost consequences for the customers who experience them are simply not counted.

At one extreme, widespread power losses resulting from major natural events (primarily storms but also hurricanes and earthquakes) are sometimes not included in the same data categories as more routine power losses. As a result, power losses from natural events are not always included in data used for cost estimates. At the other extreme, momentary fluctuations in power (or

\footnotetext{
${ }^{3}$ The North American Electric Reliability Council is a source of information on major customer outages stemming from events affecting the bulk transmission system (for example, an unplanned loss of demand greater than 300 MW.) See http://www.nerc.com/ oc/pds.html. However, most outages are small and occur on utility distribution systems. Utility reporting systems, in principle, record both types of outages.
} 
power-quality events) and momentary interruptions or losses of power for less than five minutes are not reported as reliability events by many utilities. Clearly, these differences in reporting conventions make it difficult to compare reliability data and performance among different utilities. ${ }^{4}$

The MAIFI index is a useful measure for assessing the frequency of momentary interruptions. However, the data are not as commonly collected and therefore more difficult to find. Consistent with IEEE's definition of a sustained interruption, a momentary outage is defined as any event lasting less than five minutes. The MAIFI index is therefore defined as,

$$
\begin{gathered}
\text { Total number of customer momentary }(<5 \mathrm{~min}) \text { interruptions for all customers } \\
\text { Total number of customers served }
\end{gathered}
$$

Nevertheless, because SAIDI, SAIFI, and MAIFI are reported as an aggregate of all events in a given year, these indices alone cannot be used to determine the frequency, duration, or timing of individual reliability events. As we will discuss next, this practice is at odds with the costs customers experience as a result of reliability events, which have been found to vary as a function of the duration and timing of reliability events.

Along the same lines, SAIDI, SAIFI, and MAIFI data do not distinguish between the types of customers experiencing reliability events. Due to the design of electricity distribution systems, larger commercial and industrial customers tend to experience fewer and shorter power interruptions than do smaller commercial and residential customers.

While SAIDI, SAIFI, and MAIFI capture those reliability events during which voltage drops to zero, for many customers, subtle deviations in power quality pose a far more significant reliability problem than these interruptions (because they occur more frequently). The most common small deviation is a voltage "sag" - a drop in (but not complete loss of) voltage for a short period of time (i.e., from a few cycles to a few seconds). ${ }^{5}$ Voltage sags can be caused by natural events (e.g., trees falling on power lines or lightning striking lines or transformers), utility activities (e.g., routine switching operations or human error), or customer activities (e.g., starting of large motors).

Despite the growing importance of power quality as a class of reliability events, the situation for information on power quality is even worse than it is for SAIDI, SAIFI, and MAIFI. Indices for power quality events are under active discussion by the industry. However, at this time, there has

\footnotetext{
4 There is some confusion in the literature regarding the definition of "sustained" and "momentary" interruptions for the purpose of reporting them as reliability events. We have relied on the IEEE Trial-Use Guide for Electric Power Distribution Reliability Indices (IEEE 1999), which defines momentary interruptions as zero-voltage (or voltage $<10 \%$ ) events lasting 5 minutes or less (no minimum duration is specified). The IEEE Recommended Practice for Monitoring Electric Power Quality (IEEE 1995) defines the duration of momentary interruptions as zero-voltage events lasting between 0.5 cycles to 3 seconds and sustained interruptions as "any interruption not classified as a momentary interruption." A momentary interruption event (for reporting purposes), therefore, may encompass more than one momentary (or sustained) interruption, provided service is restored within 5 minutes.

${ }^{5}$ EPRI's landmark study of power quality found that voltage-related power quality events accounted for $90 \%$ of all power quality events (Electrotek Inc. 1996).
} 
been only one comprehensive study of power quality and the data collected for it are now over 10 years old (Electrotek Inc. 1996). Currently, there are no ongoing data collection efforts for power quality in the public domain (Electric Power Research Institute 2003).

In addition to data availability concerns, some of the challenges for studies of power quality include:

- Power quality events can be caused by activities on both sides of the customer meter.

- Utility distribution systems were never designed to provide perfect power quality.

- Sensitivity to power quality events depends on the characteristics of the customer.

\subsection{The Cost of Reliability Events}

Estimating the costs that customers experience as a result of outages involves several sources of uncertainty. Typically, outage-cost estimates are based on surveys that assess the costs that customers say they will experience under different outage circumstances (Lawton et al. 2003). One source of uncertainty in these estimates is the degree to which the costs customers report in surveys under hypothetical circumstances correspond with the costs they actually would experience under such circumstances. No studies have been done to validate the results obtained from these surveys and this is a significant source of uncertainty in the cost estimates that have been prepared to date.

Assessing actual costs is complicated by the differing impacts of reliability events on the different classes of customers - residential, commercial, or industrial - that are affected by an event. We break costs down into three categories: costs borne by residential customers, costs borne by non-residential (commercial and industrial or C\&I) customers, and costs borne by the infrastructure of society in general.

Costs experienced by residential customers are difficult to quantify. Although out-of-pocket costs for consumable goods, such as candles, flashlight batteries, prepared food (i.e., eating out), and food spoilage, are easy to quantify, the other "costs" borne by residential customers are experiential in nature, such as resetting clocks, changing plans, and coping with inconvenience, fear, anxiety, etc. Analytical techniques to estimate these costs typically involve contingent valuation, which includes so-called "willingness to pay" and "willingness to accept" approaches as a means of addressing experiential costs in deriving outage costs for residential customers. The findings developed through application of contingent valuation methods have been controversial due to concerns regarding bias in the responses provided by customers to the hypothetical nature of situations they must rely on. 


\section{Customer Vulnerability to Power Quality Events}

The cost of power quality events is not included in the LBNL base-case estimate of the cost of power interruptions because systematic information on the frequency and nature of power quality events is not readily available and because the impact of these events on customers' equipment is both changing and not spread evenly throughout the population.

Assessment of power quality involves looking at electromagnetic deviations from the ideal service that the U.S. electricity distribution system is designed to provide: a pure 60-cycle per second alternating current at a designated voltage (120 volts for residential customers or 480 volts for many commercial or industrial customers). Any deviation from this standard that causes customers' equipment to fail or malfunction is considered a power quality "event."

Deviations in voltage are the most frequent power quality event. The IEEE classifies these events according to both the duration of an event, as well as by the degree of voltage deviation from the service standard. See Figure 1.

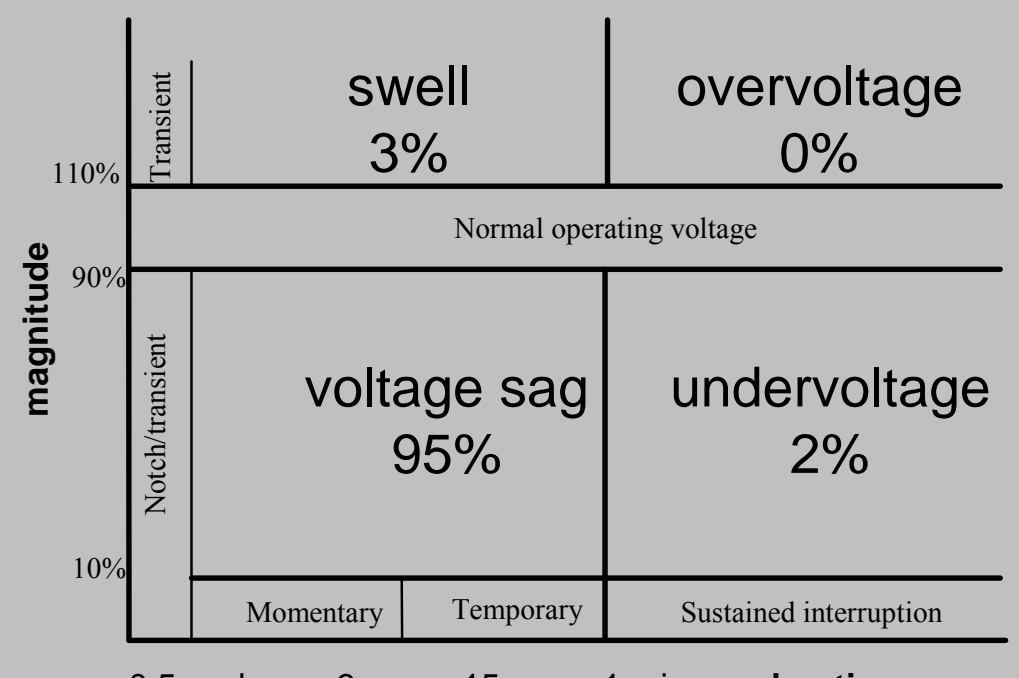

\section{5 cycle $3 \mathrm{sec} 15 \mathrm{sec} 1 \mathrm{~min}$ duration \\ Figure 1. Voltage Deviation as a Function of Duration of Event}

Although in the past most electricity-consuming devices could "ride through" voltage sags (e.g., a light bulb might dim momentarily), many of the electricity-consuming devices associated with today's digital economy (e.g., equipment controlled by programmable logic chips) cannot tolerate a partial drop in voltage for even a fraction of a second. Voltage sags may cause this equipment to shut down and remain off even after service is restored to normal levels. Voltage sags are rapid and not easily detectable by an untrained observer, and so consumers may not realize that a power quality 'event' caused their equipment to fail or stop operating. Currently, voltage sags are not included in reliability statistics reported by utilities (e.g., SAIDI, SAIFI, and MAIFI).

In addition to the absence of systematic information on the frequency and type of power quality events, the vulnerability of electricity-consuming devices to these events is changing. Industry has developed guidelines that can be used to specify the tolerance of equipment to voltage sags of varying types. Figure 2 includes an example of such a guideline, known as the CBEMA curve. This guideline specifies a region or class of voltage events (in terms of duration and degree of voltage deviation) within which equipment is designed to operate normally. Figure 2 also displays power quality events recorded during a recent DOE-sponsored pilot demonstration of a new power quality monitoring system in California's Silicon Valley. With respect to these guidelines, the figure confirms that equipment specified to meet them should ride-through many of the recorded events. However, the figure also confirms that there were many events outside the "zone of protection" specified in the guideline. A total of 263 sags and 51 interruptions were recorded; of these, 104 were events below the CBEMA curve. 
This figure illustrates a key challenge for estimating the cost of power quality events. Information is needed on the frequency and type of power quality events experiences by customers, as well as on the vulnerability of customers' equipment to these events. As we were not able to develop systematic information on either type of information, we did not include an estimate of the cost of power quality events in the LBNL base-case.

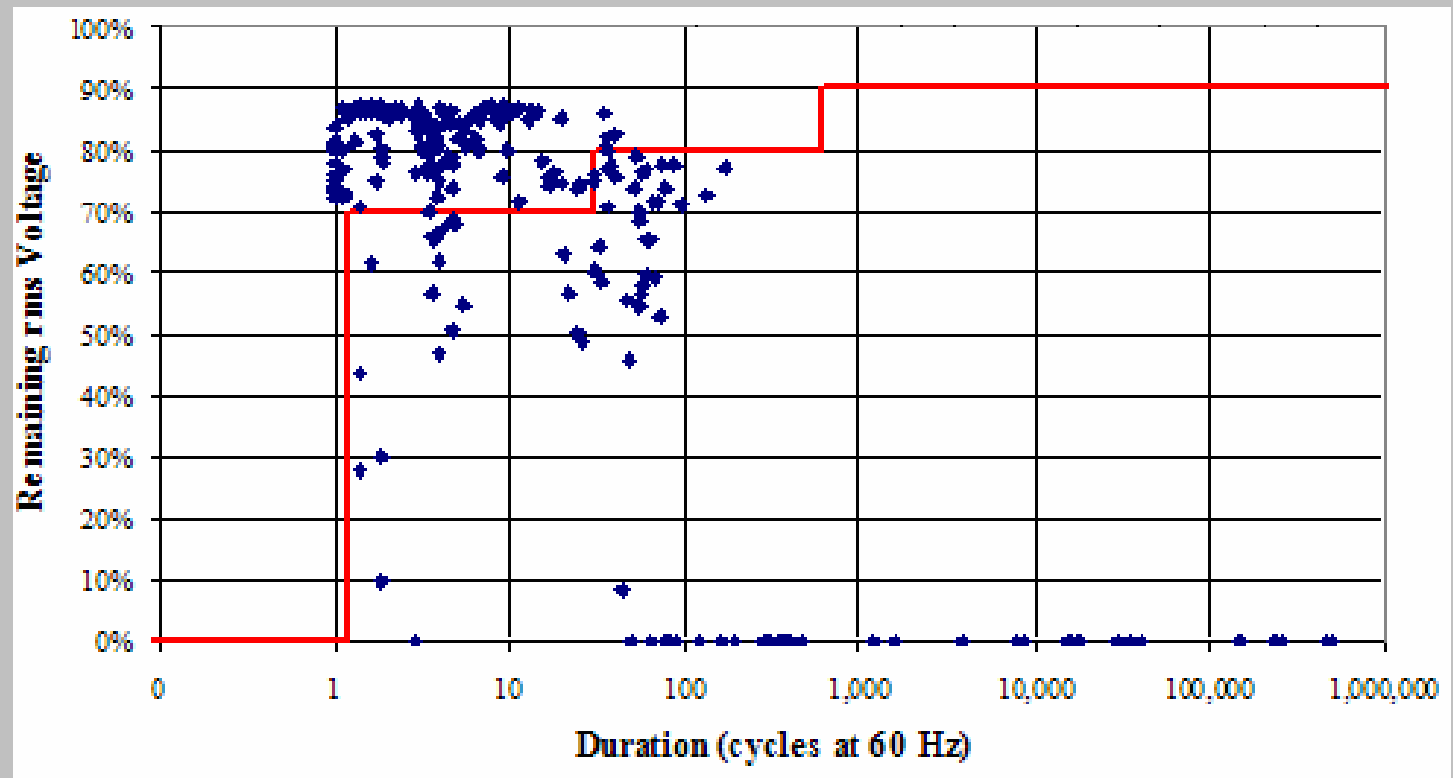

Source: (Eto et al. 2004)

Figure 2. Findings from a Recent Demonstration of a Power Quality Monitoring System in California's Silicon Valley Displayed Against the CBEMA Curve.

Costs experienced by non-residential customers or firms are, in principle, simpler to estimate. Basic accounting categories, including labor and materials costs and lost revenues, are straightforward (though not necessarily easy) to determine for work interruptions caused by power losses. Significant work has been done to articulate clear cost categories for recording this information. ${ }^{6}$ It is important to assess these costs carefully and focus on net losses; for example, lost revenues might be partially offset by scheduling an extra shift to make up for lost production.

A subtle issue that has gained increasing recognition is that losses to businesses are not in direct proportion to the duration of a reliability event (Eto et al. 2004). The relevant factor is the length of business or production downtime caused by an outage of any length. A partial loss of voltage or voltage sag can cause the same amount of downtime as a complete one hour loss of power, if, for example, machines need to be rebooted or production needs to be restarted. This issue poses a major challenge in estimating the economic cost of power interruptions and power quality.

A final category of costs applies when reliability events are widespread and last for extended periods of time. These are costs borne by the "infrastructure" of society, not by individual residential and non-residential customers. Examples of infrastructure costs include costs associated with emergency response or public health and safety activities that may be

\footnotetext{
${ }^{6}$ See, for example, (Sullivan and Keane 1995).
} 
necessitated by widespread outages. ${ }^{7}$ Surveys that ask customers to report the impacts of reliability events on their individual activities will never capture these costs.

\subsection{Vulnerability to Reliability Events}

The economic cost of reliability events has led many customers to invest in a wide variety of technologies and to take other measures to reduce their vulnerability to reliability events. At one end of the spectrum, back-up or stand-by generators are probably the most well-known customer investment. However, strip surge protectors should also be viewed in this same category. In between, there are a host of energy storage technologies, such as batteries, that can reduce a customer's vulnerability to power interruption and power quality events. And for power quality especially, there are a host of measures associated with improved grounding practices customers can take to reduce the frequency of these events.

Unfortunately, data on customer investments and other efforts to reduce vulnerability to reliability events are not widely available. Limited market research is available on annual sales of some of these technologies. There have been some systematic efforts to assess the overall vulnerability of customers to reliability events that focus on specific processes (e.g., cleanrooms) or equipment types (e.g., office equipment) that may be especially sensitive to these issues. For more information, please refer to Eto et al. 2001.

\footnotetext{
7 Another factor complicating assessment of infrastructure costs associated with outages is that most large outages are the result of natural events, such as major storms. In these situations, the infrastructure costs (e.g., emergency response, health/human safety) stemming from the loss of electric service are difficult to separate from the (typically, larger) costs associated with addressing the direct effects of the initiating event itself (e.g., storm damage, flooding, etc.). There have been very few instances, for example, where loss of life has been attributing uniquely to the loss of electric service.
} 


\section{Assessing Recent Estimates of the Economic Cost of Reliability Events}

This section reviews and analyzes three recent and widely cited published estimates of the economic cost of power interruptions and power quality to U.S. electricity customers. In Section 3 , we review how others have attempted to address the data and estimation issues identified in this section - e.g., to reconcile differing customer and customer class definitions, address inconsistencies in reporting of outage frequency that might result in omission of short-duration or natural-event outages, and to account for what outage costs are and are not included in reported data. Our analysis is based on the framework and discussion of data limitations described in the previous section. The three estimates are:

- Clemmensen (1993), which was cited extensively by EPRI and others throughout the 1990s

- Swaminathan and Sen (1998), a Sandia National Laboratory report developed for DOE

- Primen (2001), which was developed for EPRI and is currently the main source cited

\subsection{Clemmensen's Estimate of \$26 Billion per Year}

Clemmensen (1993) provided the first-ever power-quality cost estimate of \$26 billion for the U.S. manufacturing sector (Electric Power Research Institute 1993). This estimate was adopted by EPRI and subsequently widely cited throughout the 1990s. It is important to note that Clemmensen's estimate was for annual spending on industrial equipment to address powerquality problems; power-quality problems normally refer to a subset of reliability problems in which voltage drops (in some cases to zero) for a very short period of time, typically for only a few cycles or seconds. Clemmensen's estimate was used by others as a measure of the aggregate cost of all power interruption and power quality problems to the U.S. economy even though Clemmensen focused only on power quality and the manufacturing sector. Clemmensen's estimate was later cited by others as the primary basis for an even higher estimate of $\$ 50$ billion for all power interruption and power quality costs in all sectors. This extrapolation was intended to take into account the effects of inflation since the time of Clemmensen's original work (Douglas 2000). ${ }^{8}$

Clemmensen estimated that 1.5 to three cents of every manufacturing sales dollar was being spent to correct power-quality problems. This estimate was based on consultations with powerquality colleagues and on work by business author Phillip B. Crosby who estimated that the expense of waste in manufacturing could reach as high as 15-25 percent of sales (Crosby 1979). ${ }^{9}$ Using 1987 manufacturing sales of $\$ 853.6$ billion and the top end of the estimated range of power-quality expenditures (three cents per dollar of sales), Clemmensen derived a total cost of $\$ 25.6$ billion (which was rounded to $\$ 26$ billion).

Based on the framework and discussion in Section 2 of this report, we offer four observations about Clemmensen's original estimate. For each point, we note the likelihood that the estimate

\footnotetext{
${ }^{8}$ This sort of misuse when citing numerical analyses is an example of a larger problem further discussed in Koomey et al. (2002) that details the many examples of the misuse of numerical facts related to energy analysis issues (Koomey et al. 2002)

${ }^{9}$ This reference was provided by Jane (Clemmensen) Thornton in personal communication to Joe Eto on June 7, 2004.
} 
tends to over- or under-estimate power interruption and power quality costs to the U.S.

1. Spending is used as a proxy for costs. From an economic perspective, this discrepancy is similar to the difference between marginal cost and marginal benefit, where spending is valued such that the last dollar spent is equivalent to the benefit from the last dollar of expenditure. That is, a rational consumer would spend no more on fixing a problem than the cost of the problem itself. ${ }^{10}$ Bias is toward underestimating total power interruption and power quality costs.

2. Power quality is only a subset of reliability events that have economic impacts on customers; power quality does not normally include losses of power for periods longer than a few seconds. Bias is toward underestimating total costs.

3. The estimate is limited to the manufacturing sector. ${ }^{11}$ Bias is toward underestimating total power interruption and power quality costs because the estimate does not include the costs from the commercial or residential sectors.

4. The estimated value of 1.5 to three cents of spending per dollar of manufacturing sales on power-quality equipment is undocumented. It was based only on experience and professional judgment. A recent survey of annual spending on power-quality equipment (by all sectors, not just manufacturing) reported $\$ 5$ billion in sales (Clemmensen et al. 1999). This recent survey suggests that the figure used in the original extrapolation to develop the 1993 estimate was too high by a factor of about five; a more appropriate range might have been 0.3 to 0.6 cents of annual spending per manufacturing dollar of sales on power-quality equipment.

\subsection{Swaminathan and Sen’s Estimate of \$150 Billion per Year}

In a Sandia National Laboratory report, Swaminathan and Sen (1998) estimate U.S. power interruption costs at $\$ 150$ billion per year. The authors obtained this estimate by extrapolating the results of a 1992 Duke Power outage cost survey to the entire U.S. based on total industrial electricity sales.

Using the framework and discussion in Section 2 of this paper, we offer the following three observations about Swaminathan and Sen's estimate. For each point, we note the likelihood that the estimate tends to over- or underestimate U.S. power interruption costs.

1. The extrapolation focused on only the industrial sector. The likelihood is that this results in underestimation of total power interruption costs because the estimate does not include the costs from the commercial or residential sectors.

2. The extrapolation assumes that the U.S. industrial sector at large experiences the same number and type of reliability events and the same costs resulting from these events as the

\footnotetext{
${ }^{10}$ However, spending may have been intended to address multiple concerns simultaneously, such as productivity improvements in addition to power-quality solutions, so the portion of the expenditure that can be allocated to address power-quality problems may be less than the total spent.

11 Interestingly, Clemmensen's original paper also estimated commercial power-quality costs at $\$ 13.3$ billion, but this figure was never added to the $\$ 25.6$ billion estimate for manufacturing facilities. The commercial-sector estimate assumed a cost of $\$ 20.24 / \mathrm{kWh}$ unserved (for a 15-minute outage, from a survey conducted in 1974), and an annual probability of 0.001 for a 15 minute interruption for 1987 commercial electricity use of 658 billion kWh.
} 
population of industrial customers in the Duke Power service territory. A recent study of customer outage costs found that there are statistically significant differences in the costs experienced by industrial customers both among different industrial sectors and among different geographic regions (Lawton et al. 2003). Given the available data, we cannot determine whether Swaminathan and Sen's assumption results in likely under- or overestimation of total power outage costs.

3. Appendix A presents data on the duration and frequency of outages from utility service territories across the U.S. These reliability index data confirm that outage characteristics are not uniform across the country. Anecdotal evidence suggests that the Southeastern portion of the U.S., where Duke Power is located, is subject to more frequent lightning storms than other parts of the U.S., which increases the likelihood that customers in Duke Power's area would experience larger numbers of lightning-related reliability events than customers in other areas of the country. If this were true, Swaminathan and Sen's use of data from Duke Power's service area would likely result in overestimation of the number of outages and therefore the costs that would be likely to apply to the country as a whole. However, based on the information available, we cannot determine conclusively what type of regionalspecific bias is introduced by the use of Duke Power service territory data.

\subsection{Primen's Estimate of \$119 Billion per Year}

In 2001, EPRI commissioned and published a report from Primen. This report is the first systematic effort to estimate the national economic cost of power interruptions including power quality (Primen 2001). Building on insights gained from an earlier EPRI-commissioned literature review (Eto et al. 2001), the Primen study addressed several shortcomings of earlier estimates:

- The Primen study was explicitly designed to develop a national estimate; it was not an extrapolation from a smaller geographically confined area, as in the Swaminathan and Sen study.

- It treated power quality along with other reliability events, such as outages, in a consistent manner.

- It was developed, initially, using statistical sampling techniques from a defined population.

The Primen study surveyed 985 firms drawn from three populations of businesses: "digital economy," "continuous process manufacturing," and "fabrication and essential services." Each firm surveyed was asked to provide cost estimates for several distinct power outage scenarios (e.g., loss of power for one second, three minutes, one hour, etc.), all on summer weekday afternoons, plus an estimate of the annual cost of power-quality events. The results from the surveys were weighted to develop estimates for the three surveyed groups. Then, the results were extrapolated to represent an estimate for the nation by assuming that the costs experienced by the non-surveyed population were 25 to 50 percent of the costs experienced by the surveyed populations. Table 2 summarizes results from the Primen study. 
Table 2. Summary of Primen Study Results

\begin{tabular}{|l|r|r|r|}
\hline & \multicolumn{1}{|c|}{$\begin{array}{c}\text { Surveyed } \\
\text { Populations }\end{array}$} & $\begin{array}{c}\text { Non-surveyed } \\
\text { Populations }\end{array}$ & \multicolumn{1}{|c|}{ Total } \\
\hline Power Outages & $\$ 46$ billion & $\$ 58-118$ billion & $\$ 104-164$ billion \\
Power Quality & $\$ 7$ billion & $\$ 8-17$ billion & $\$ 15-24$ billion \\
\hline Total & $\$ 53$ billion & $\$ 66-135$ billion & $\$ 119-188$ billion \\
\hline
\end{tabular}

Based on the framework and discussion in Section 2, we offer the following observations about the Primen estimate. For each point, we note the likelihood that total U.S. power interruption and power quality costs were under- or overestimated.

1. The Primen study assumes that outage costs experienced on summer weekday afternoons can be used to assess outage costs experienced at other times during the year. Most surveys of customer outage costs have found very large differences in costs depending on the time of day, week, and season during which an outage occurs (Eto et al. 2001). Costs associated with outages on summer weekday afternoon are typically the highest because of high electricity usage during this time, largely because virtually all businesses are in full operation and electricity use for space conditioning is at a maximum. Unreliability is not confined to summer afternoons and the use of summer weekday outage cost estimates likely results in overestimation of total power interruption and power quality costs.

2. The Primen study assumes that outage costs experienced by the non-surveyed population are 25 to 50 percent of the costs experienced by surveyed firms. Surveys of outage costs that have controlled for differences in firms have found that costs can differ by a factor of ten to one or more among firms (Eto et al. 2001). ${ }^{12}$ The populations surveyed were explicitly selected because they are known to be sectors that are especially vulnerable to electricity reliability events. The resulting bias cannot be established conclusively but likely results in overestimation of total power outage costs.

3. The study did not consider the costs of power interruptions and power quality to residential customers. The result of this omission is likely an underestimation of total power interruption and power quality costs.

\footnotetext{
12 The Eto et al. 2001 study also explored sensitivity to outage costs as a function of process (e.g., cleanrooms), which suggests that it also is important to consider variation in sensitivity within NAICS codes.
} 


\section{Deriving a New Estimate of the Economic Cost of Power Interruptions to U.S. Electricity Consumers}

This section presents a new estimate of the economic cost of power interruptions to U.S. electricity consumers using the framework introduced in Section 2, not including power quality. Our estimate is based on a review of the best data available in the public domain. Table 3 summarizes the data we used to develop a new estimate of the economic cost of power interruptions to U.S. electricity consumers. As described earlier, the best data available remain subject to important limitations. Accordingly, we identify and explore some of these uncertainties in Section 5.

Table 3. The Data Used to Develop a National Estimate of the Cost of Power Interruptions

\begin{tabular}{|c|l|}
\hline Customers & $\begin{array}{l}\text { Customer classes (residential, commercial, and industrial) and populations are } \\
\text { defined and estimated using data from the U.S. Energy Information } \\
\text { Administration for 10 regions of the U.S. (with separate treatment for } \\
\text { California.) }\end{array}$ \\
\hline $\begin{array}{c}\text { Duration and } \\
\text { Frequency of } \\
\text { Reliability } \\
\text { Events } \\
\text { line search (N = 162,162, and 52, respectively.) }\end{array}$ & $\begin{array}{l}\text { Within each region, all customers are assumed to experience the same duration } \\
\text { and frequency of reliability events because current reporting of SAIDI, SAIFI, } \\
\text { and MAIFI does not distinguish between customer classes. }\end{array}$ \\
\hline $\begin{array}{c}\text { Cost of } \\
\text { Information on power quality events is not included. }\end{array}$ \\
$\begin{array}{c}\text { Events } \\
\text { Eustomer damage functions for three customer revenue classes (residential, } \\
\text { small and medium C\&I, and large C\&I) are taken from a recent national study } \\
\text { of utility outage cost surveys conducted by Population Research Systems and } \\
\text { LBNL (Lawton et al. 2003). In total, over 60,000 survey responses from 24 past } \\
\text { utility studies were combined to support the estimation of customer damage } \\
\text { functions. }\end{array}$ \\
$\begin{array}{l}\text { Customer damage functions express the cost of an outage as a function of } \\
\text { outage duration, season, time of day, annual electricity use, and depending on } \\
\text { the customer class, household income or number of employees. }\end{array}$ \\
\hline $\begin{array}{c}\text { Vulnerability } \\
\text { to Reliability } \\
\text { Events }\end{array}$ & $\begin{array}{l}\text { Vulnerability is not used in this study due to the absence of reliable information } \\
\text { on customer investments in reliability-enhancing technologies (e.g., back-up } \\
\text { generators and energy storage) and related measures. }\end{array}$ \\
\hline
\end{tabular}

\subsection{Customers by Customer Class and Region}

This sub-section explains how customers are defined in our analysis and discusses the assumptions made in partitioning the population of customers into regions.

\footnotetext{
13 The trimmed mean is a simple data analysis approach designed to remove outliers within a set of observations by deleting a specified percentage of the highest and lowest data points and recalculating the mean of the reduced population of data points.
} 
This study uses residential, commercial, and industrial electricity demand sectors to describe the customer classes. Data on customer population are taken directly from EIA's Electric Sales and Revenue publication (Energy Information Administration 2001b):

- The residential energy-consuming sector consists of living quarters for private households.

- The commercial energy-consuming sector consists of facilities that provide services and includes the equipment of: businesses; federal, state, and local governments; and other private and public organizations, such as religious, social, or fraternal groups, including institutional living quarters and sewage-treatment facilities.

- The industrial energy-consuming sector consists of all facilities and equipment used for producing or assembling goods. This sector encompasses: manufacturing [North American Industry Classification System (NAICS) codes 31-33]; agriculture, forestry, and hunting (NAICS code 11); mining, including oil and gas extraction (NAICS code 21); natural gas distribution (NAICS code 2212); and construction (NAICS code 23). Our definition of this category differs from EIA's in that we also include electricity sales sold to/consumed by public street and highway lighting, public authorities, railroads and railways, and users classified as "Other" by EIA.

This study partitions the U.S. into regions so that we can represent variations in outage costs in different areas of the country. The regions correspond to U.S. Census Divisions as mapped by EIA with a slight variation in the Pacific region where we extract California and treat it as a separate region because this is where most of the Pacific region population resides. Figure 3 illustrates the regions used in our study.

The customer population data were taken from EIA's Electric Sales and Revenue publication (Energy Information Administration 2003b). The data are reported for year 2001 by state and by demand sector (residential, commercial, and industrial). Using a modified version of EIA's mapping of U.S. Census Division regions, Table 4 shows the number of customers in each region and each sector, including the percent of total by region and sector.

Table 4. Number of Customers by Region and Sector in 2001

\begin{tabular}{|c|c|c|c|c|c|}
\hline & RESIDENTIAL & COMMERCIAL & INDUSTRIAL & ALL SECTORS & $\%$ of Total \\
\hline U.S. ESTIMATE & $\begin{array}{r}114,317,707 \\
(87 \%)\end{array}$ & $\begin{array}{r}14,939,895 \\
(11 \%)\end{array}$ & $\begin{array}{r}1,582,573 \\
(1 \%)\end{array}$ & $130,840,175$ & \\
\hline \multicolumn{6}{|l|}{ BY REGION } \\
\hline New England (1) & $5,822,935$ & 714,049 & 62,677 & $6,599,661$ & $(5 \%)$ \\
\hline Middle Atlantic (2) & $15,045,495$ & $2,127,033$ & 103,713 & $17,276,241$ & $(13 \%)$ \\
\hline East North Central (3) & $18,705,754$ & $2,110,172$ & 158,780 & $20,974,706$ & $(16 \%)$ \\
\hline West North Central (4) & $8,287,837$ & $1,139,609$ & 170,937 & $9,598,383$ & $(7 \%)$ \\
\hline South Atlantic (5) & $22,473,797$ & $2,842,220$ & 270,840 & $25,586,857$ & $(20 \%)$ \\
\hline East South Central (6) & $7,356,975$ & $1,135,507$ & 78,545 & $8,571,027$ & $(7 \%)$ \\
\hline West South Central (7) & $12,883,403$ & $1,722,873$ & 292,035 & $14,898,311$ & $(11 \%)$ \\
\hline Mountain (8) & $7,368,280$ & $1,001,310$ & 212,842 & $8,582,432$ & $(7 \%)$ \\
\hline Pacific (9) & $3,922,426$ & 494,778 & 66,699 & $4,483,903$ & $(3 \%)$ \\
\hline California (10) & $11,841,144$ & $1,559,258$ & 154,261 & $13,554,663$ & $(10 \%)$ \\
\hline
\end{tabular}




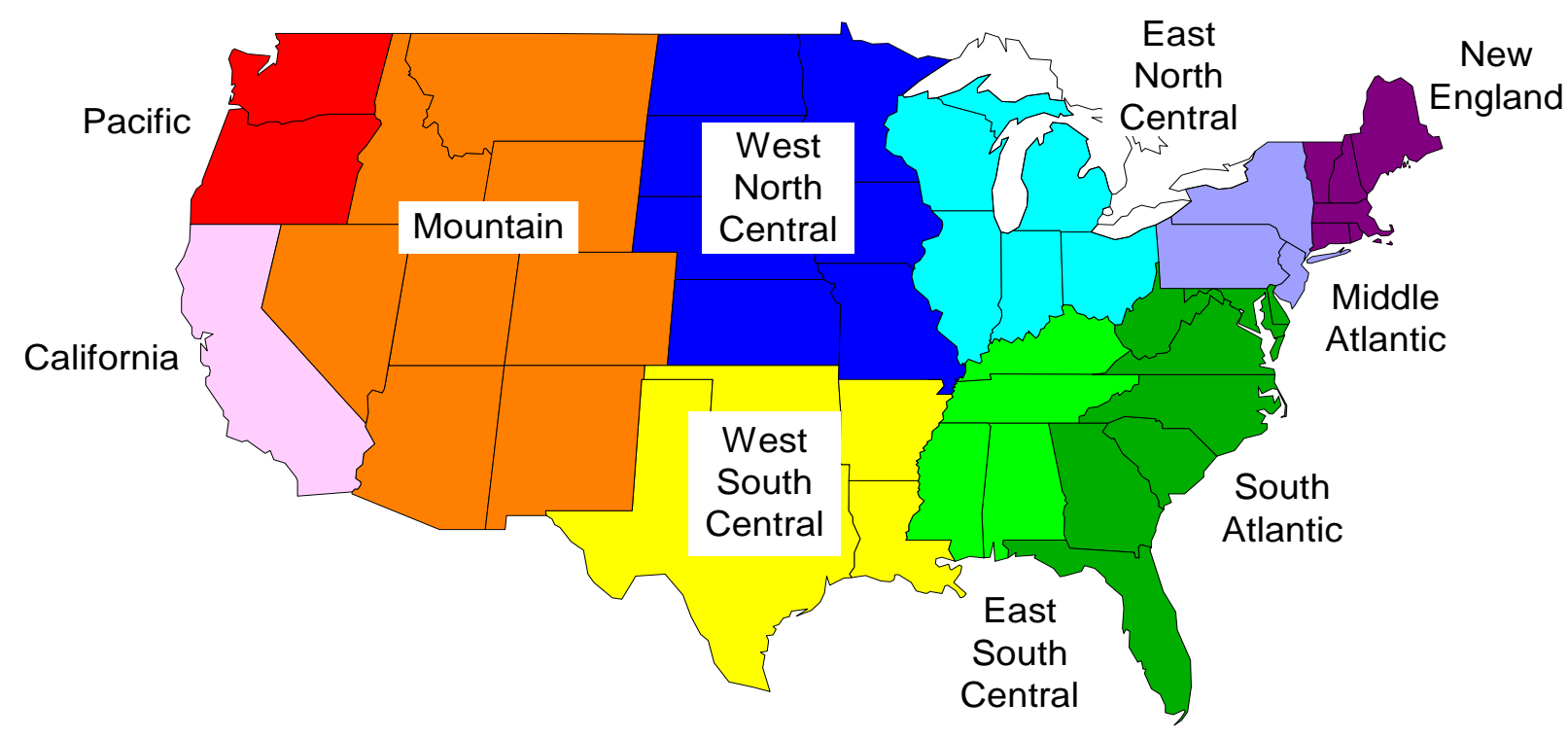

Figure 3. Map of Modified Census Division Regions

\subsection{The Duration and Frequency of Reliability Events}

Despite the existence of well-defined indices for a majority of reliability events, information on U.S. reliability events is not collected systematically or consistently. The National Regulatory Research Institute reports that only 23 of the 40 surveyed states require annual reporting of reliability statistics (National Regulatory Research Institute 2000). As a result, deriving reliability event data to represent all U.S. regions poses a challenge.

We conducted an on-line search to gather publicly available data on reliability events. We then reviewed the data and implemented a simple data analysis technique to eliminate outliers. Finally, we compared our findings to other published reports on the national duration and frequency of outages.

We obtained 181, 180, 56 observations, for 39, 38, and 9 independent sources of SAIDI, SAIFI, and MAIFI data, respectively, from our on-line search. Figures 4 and 5 present our findings as cross-tabulations. Appendix A contains the regional SAIDI, SAIFI, and MAIFI data we collected.

To address bias introduced by extreme outliers, a simple data analysis procedure called "trimmed means" was used to remove the highest and lowest five percent of observations and then calculate the means of the resulting, reduced population of observations (Mosteller and Tukey 1977). Table 5 compares the means and standard deviations for SAIDI, SAIFI, and MAIFI calculated from both the total set of observations and the "trimmed" set of observations.

Table 5 shows the variation of the means and standard deviations with and without the trimming process. Here we can see that removing the highest and lowest five percent of data points in each data set has a noticeable effect on the resulting average duration of outages. By removing the outliers, the SAIDI average decreases from 122 minutes to 106 minutes, while the SAIFI and MAIFI means change very little. More interesting is the significant reduction in the magnitude of 
the standard deviation with these three indices. The standard deviation for both SAIDI and SAIFI are roughly halved when ten percent of the outlying data points are removed and is reduced by more than ten percent for MAIFI. This suggests that trimming the highest and lowest five percent of data points helps to significantly improve the robustness of our means.

Table 5. Summary of Trimmed Mean and Total Mean Reliability Event Data

\begin{tabular}{|c|c|c|c|}
\hline & SAIDI & SAIFI & MAIFI \\
\hline Trimmed Mean & 106 min. & 1.2 & 4.3 \\
(Standard Deviation) & $(54 \mathrm{~min})$. & $(0.5)$ & $(3.6)$ \\
\hline Total Mean & $122 \mathrm{~min}$. & 1.3 & 4.6 \\
(Standard Deviation) & $(115 \mathrm{~min})$. & $(1.0)$ & $(4.1)$ \\
\hline
\end{tabular}

Figures 4 and 5 also include the trimmed outliers to illustrate how much the data can vary and skew the estimated mean. Trimming five percent of the highest and lowest data points provides a more representative average value for these indices by removing the influence of extreme events. For SAIDI, the trimmed mean is 106 minutes as shown by the line, with a standard deviation of 54 minutes and for SAIFI, the trimmed mean is drawn in at 1.2 with a standard deviation of 0.5 .

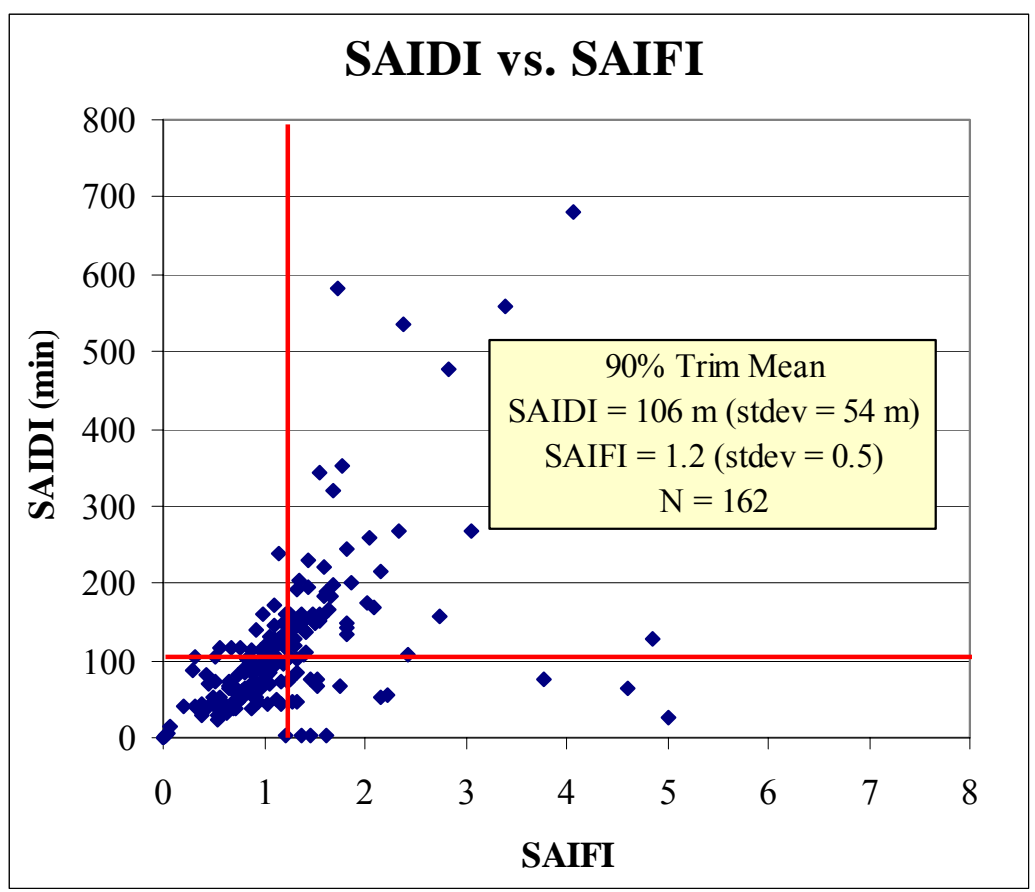

Figure 4. Scatter Plot of SAIDI vs. SAIFI

Figure 5 shows a cross-tabulation of SAIFI vs. MAIFI to identify whether the frequency of sustained interruptions is at all related to the frequency of momentary interruptions. Interestingly, there does not seem to be any visible patterns of increasing/decreasing MAIFI with changes in SAIFI; the occurrence of sustained outages does not appear to have any noticeable impact on the 
number of momentary outages. The trimmed mean is 4.3 as shown by the line, with a standard deviation of 3.6 based on reducing the number of data points from 56 to $52 .{ }^{14}$

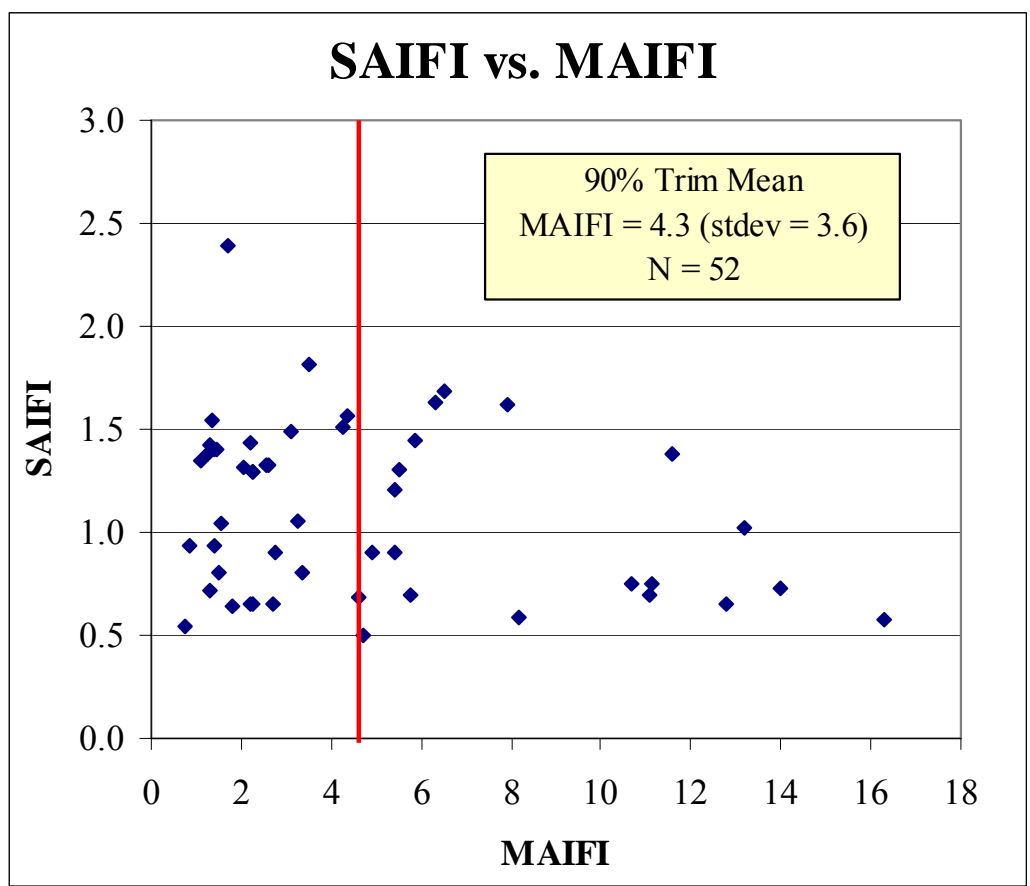

Figure 5. Scatter Plot of SAIFI vs. MAIFI

Several studies have also examined national statistics on SAIDI, SAIFI, and MAIFI. Table 6 compares the findings from these studies to the trimmed means used in our analysis. The trimmed means of 106 minutes, 1.2 and 4.3 for SAIDI, SAIFI, and MAIFI, respectively, are very similar to the estimates reported from external studies shown in Table 6. Hence, our trimmed means are reasonable estimates for calculating the cost of power interruptions to U.S. electricity customers.

Table 6. Summary of U.S. Reliability Event Estimates by External Studies

\begin{tabular}{|c|c|c|c|}
\hline & SAIFI & SAIDI & MAIFI \\
\hline EPRI Report $^{1}$ & 1.1 & 107 & \\
\hline IEEE 1995 Survey $^{2}$ & 1.3 & 120 & 5.5 \\
\hline EEI Annual Report $^{3}$ & & & \\
1998 & 1.2 & 118 & 5.4 \\
1999 & 1.4 & 101 & 11.6 \\
\hline
\end{tabular}

${ }^{1}$ Source: (Electric Power Research Institute 2003)

${ }^{2}$ Source: IEEE 1995 Survey (http://resourceinsight.com/work/naruc_pbr_97.pdf)

${ }^{3}$ Source: Power Sources Manufacturer's Association (http://www.psma.com/HTML/newsletter/Q2_2001/page11.html)

Given the disaggregated framework we have established for evaluating the aggregate cost of power interruptions to U.S. electricity customers, it would be highly desirable to utilize distinct

\footnotetext{
14 This figure does not show the SAIFI trimmed mean in this figure because of the reduced number of points used to accommodate the MAIFI data.
} 
SAIDI and SAIFI values for each customer class. Unfortunately, available literature does not provide reliable information disaggregated in this manner. For the purposes of this evaluation we have assumed uniform application of SAIDI and SAIFI values to all customer classes. Anecdotal evidence suggests that large customers experience higher levels of reliability; hence, our assumption likely exerts an upward bias on our estimate of the cost of power outages. This presumption is further examined in Section 5 when we explore varying reliability event assumptions by customer class.

We did not find similarly comprehensive data on the frequency of power quality events and so elected not to include the costs of power quality events in our initial estimate - a task we leave to future efforts.

\subsection{The Cost of Reliability Events}

A major challenge for estimating the cost of power interruptions and power quality is the limited information available on the cost of reliability events. We addressed this limitation by relying on findings from a recent study that combined and jointly analyzed the large body of work conducted by utilities to examine the cost of power interruptions to their customers.

Our cost analysis incorporates findings from a recent study published by Population Research Systems (PRS), LLC and Lawrence Berkeley National Laboratory (Lawton et al. 2003), which we will refer to as the "PRS Study." The PRS study is a meta-analysis of 24 independent customer surveys conducted by eight electric utility companies in the U.S. over the past 13 years. Multiple regression analysis techniques were used to combine the survey data into equations that express outage costs per customer as a function of multiple, independent parameters. For more information on this study, please see the text box.

The PRS study developed analytic expressions, called customer damage functions, that express customer outage costs as a function of customer class, region, event duration, and other descriptive variables based on a data set of survey responses from more than 2,000 large C\&I, 5,200 small and medium C\&I, and 11,000 residential customers. The cost-per-outage-percustomer data were normalized and reported in year-2002 Consumer-Price-Index (CPI)-weighted dollars.

In order to utilize the information developed in the PRS study, we had to reconcile two aspects of the Tobit equations with the data available for our estimate. First, we had to develop a mapping between the regions used in the PRS study with the demographic and firmographic data available for our estimate. Second, we had to develop a consistent method for using the time of day/week and seasonal variables with the information we had on outage frequency, which does not include information on the time when reliability events occur.

\subsubsection{Accounting for Regional Variation in Reliability Event Costs}

In order to estimate the cost of power interruptions to U.S. electricity customers, we needed to reconcile differences in how the regions were defined in the Tobit regression equations with the collected data we needed in order to estimate this per-outage cost. This sub-section describes how we mapped the regions among these demographic and firmographic data. 
Regional variations in outage costs are addressed in our analysis (as described below). We had to determine regional costs for California because we separated California from the Pacific Census Division. To represent California costs, we used energy consumption and worker and establishment population statistics from the Pacific region when California data could not be found. The residential-sector information necessary for the Tobit regression equation was available for California.

Industrial sector annual energy use per worker was available for the four regions that are traditionally reported for the manufacturing sector (West, Midwest, Northeast, and South). The value reported for each manufacturing region was used for all Census Divisions that fall within that manufacturing region. For example, the industrial sector annual energy consumption per worker for the New England and Middle Atlantic Census Divisions is the value for the Northeast-manufacturing region, which includes both of these Census Divisions. Figure 6 shows the relationship between Census Divisions and manufacturing regions.

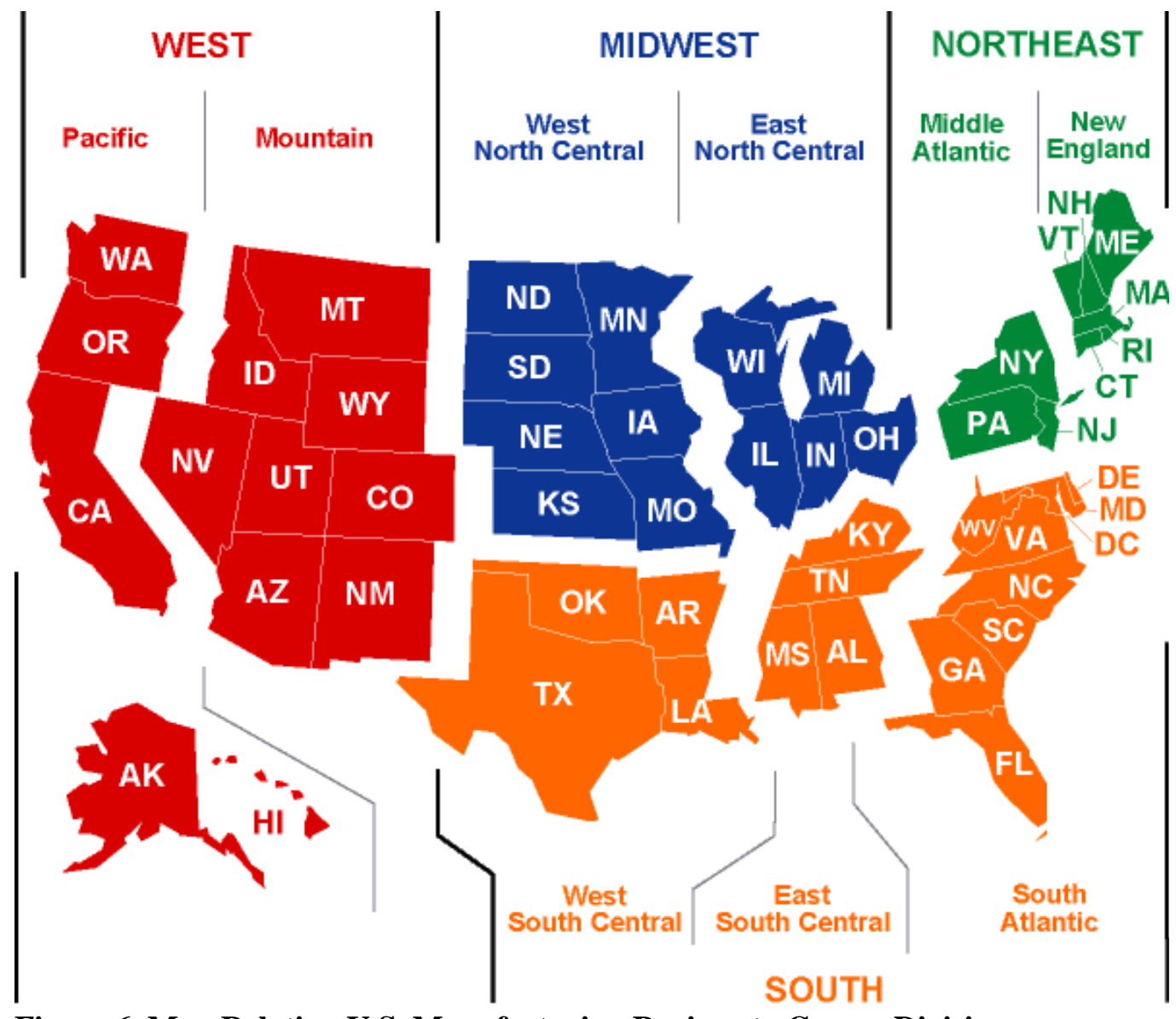

Figure 6. Map Relating U.S. Manufacturing Regions to Census Divisions 


\section{A Framework and Review of Customer Outage Costs: Integration and Analysis of Electric Utility Outage Cost Surveys by L. Lawton, A. Katz, M. Sullivan, K. VanLiere, and J. Eto.}

As a first step toward addressing the current absence of consistent data needed to support better estimates of the economic value of electricity reliability, the U.S. Department of Energy commissioned Lawrence Berkeley National Laboratory and Population Research Systems (PRS) to review and integrate available information on customer electricity outage costs.

Over the past 20 years, electric utilities have developed the largest empirical body of work on customer electricity outage costs. Called "value of service" studies, utilities have used statistical sampling and survey methods to poll their customers on the cost of outages. Survey methods take the direct approach of asking customers about their reliability experiences and perceptions. Surveys can take one of two approaches: direct costing (also referred to as enumeration or cost decomposition) or contingent valuation.

In direct costing, customers are asked to estimate expenditures for a series of components, such as lost product, spoilage, damage to equipment, etc. In general, this method works better for commercial and industrial customers, the bulk of whose costs are monetary, than for residential customers, whose largest cost is often inconvenience. Contingent valuation methods ask customers how much they would be willing to pay to avoid an event (willingness to pay) or how much they would be willing to accept in compensation for an event that has occurred (willingness to accept).

Twenty-four studies, conducted by eight electric utilities between 1989 and 2002 representing residential and commercial/industrial (small, medium and large) customer groups, were chosen for analysis. The studies cover virtually the entire Southeast, most of the western U.S., including California, rural Washington and Oregon, and the Midwest south and east of Chicago. All variables were standardized to a consistent metric and dollar amounts were adjusted to the 2002 Consumer Price Index. The data were then incorporated into a meta-database where each outage scenario (e.g., the loss of electric service for one hour on a weekday summer afternoon) is treated as an independent case or record both to permit comparisons between outage characteristics and to increase the statistical power of analysis results. Over 60,000 customer survey responses were collected.

Tobit regression models were used to estimate customer damage functions. ${ }^{15}$ A customer damage function expresses customer outage costs for a given outage scenario and customer class as a function of location, time of day, consumption, and business type. One can use the damage functions to calculate outage costs for specific customer types. For example, using the customer damage functions, the cost experienced by an "average" customer resulting from a 1 hour summer afternoon outage is estimated to be approximately $\$ 3$ for a residential customer, $\$ 1,200$ for small-medium C\&I customer, and \$8,200 for large C\&I customer.

Table 7 lists the predictors of outage cost (also known as "parameters") by customer class in the Tobit regression equations. The intercept represents the point at which the plotted line crosses the y axis (the y-axis-intercept point, $\beta o$ ) from the following standard statistical Tobit multiple regression expression which is not linear due to the logarithmic nature of outage costs:

$$
Y=\operatorname{Exp}\left[\beta_{o}+\beta_{1} \mathrm{X}_{1}+\beta_{2} \mathrm{X}_{2}+\ldots . .+\beta_{n} \mathrm{X}_{n}+\varepsilon\right]+e
$$

where $X_{n}$ is the independent variable, $\beta_{\mathrm{n}}$ is the regression coefficient for each predictor, and $\varepsilon$ and e represent error terms. This intercept point where the trend line for the points in the plot of outage costs crosses the $y$-axis is a starting point for the outage cost estimate, which is then refined and adjusted according to the other parameters listed in Table 7.

\footnotetext{
15 The Tobit regression is named for its developer, James Tobin and for the probit analysis methodology that Tobin incorporated into regression. Probit analysis calculates the probability of an event happening or not happening. Tobin developed his hybrid approach of regression and probit analysis to account for predictor variables that can never fall below zero, e.g. the variable of spending for cases in which spending less than zero does not make sense.
} 
Table 7 summarizes the various independent parameters included in the cost damage functions. "Duration" is the length of outage in hours; the duration squared term is included in the Tobit regression results because outages costs are not monotonic with respect to time. The squared parameter in the equation adjusts the predicted interruption cost to reflect the declines that are typically observed after outage costs reach their maximum.

"Interaction duration and $\mathrm{kWh}$ " is the mathematical product of duration and annual $\mathrm{kWh}$ consumption; this predictor is included because the effect of duration on interruption cost increases with customer usage or size.

Table 7. Summary of Tobit Regression Parameters

\begin{tabular}{|l|rrr|}
\hline \multicolumn{1}{|c|}{ Predictor } & Residential & Commercial & Industrial \\
\hline Intercept & 0.2503 & 6.48005 & 7.7954 \\
Duration (hours) & 0.2211 & 0.38489 & 0.5753 \\
Duration (hours) Squared & -0.0098 & -0.02248 & -0.0338 \\
Number of Employees & & 0.001882 & 0.0007 \\
Annual kWh (MWh for Resd.) ${ }^{1}$ & 0.0065 & 0.0000017 & $2.52 \mathrm{E}-08$ \\
Interaction Duration and kWh $^{1}$ & & $9.46 \mathrm{E}-08$ & $-1.8 \mathrm{E}-09$ \\
Morning & -0.0928 & -0.6032 & -0.5624 \\
Night & -0.1943 & -0.91339 & -1.3857 \\
Weekend & -0.0134 & -0.52041 & -0.7149 \\
Winter & 0.1275 & 0.37674 & 0.8992 \\
Log of Household Income & 0.0681 & & \\
Southeast & 0.2015 & & \\
West & -0.1150 & & \\
Southwest & 0.5256 & & \\
\hline
\end{tabular}

${ }^{1} 1 \mathrm{kWh}=1,000$ watt-hours, $1 \mathrm{MWh}=1,000,000$ watt-hours

Source: Lawton et al. 2003.

The "morning," "night," "weekend," and "winter" flags can be turned "on" (set to one) to denote that an outage is occurring during the given time period or "off" (set to zero) to denote that the outage is not occurring during that time period. These parameters are weighted based on the number of hours that each of the time periods constitute annually; these time periods are derived from permutations of these four parameters and are further explored in our sensitivity analysis.

The "log of household income" is the logarithmic transformation of household income used to correct for skewness in the household income parameter.

The "southeast," "west," and "southwest" parameters can also be turned on or off to identify the region for which the regression is being performed. When all three regional parameters are set to zero, the equation is solved for the north region. The regions included are those for which outage cost data were collected in the PRS meta-analysis study (Lawton et al. 2003).

In order to estimate the outage cost for each sector, assumptions were made regarding some of the parameters defined in the Tobit regression equations. For residential-sector predicted outage costs, we gathered data for annual energy consumption per customer from the 1997 edition of the Residential Energy Consumption Survey (RECS) by Census Division (Energy Information Administration 2003a). We gathered household income data from the U.S. Census Bureau as a 
three-year average median ${ }^{16}$ from 1999-2001 (reported in year-2001 U.S. dollars) by state and aggregated into Census Divisions (U.S. Census Bureau 2002).

The southeast, west, and southwest parameters were used when estimating the predicted outage costs for these regions. The southeast parameter was used for the South Atlantic and East South Central Census Divisions, and the west and southwest parameters was used for the California and Mountain Census Divisions, respectively. As a result, the predicted outage cost takes into account the regional variations associated with electricity outages in the U.S.

For the commercial sector, the predicted outage cost was based the annual electricity consumption per building and the number of employees per commercial building. The consumption and employee population data were obtained from the Commercial Buildings Energy Consumption Survey (CBECS) 1999 by Census Division (Energy Information Administration 2002).

For the industrial sector, data were collected on annual electricity consumption and number of employees per establishment. The electricity consumption data were obtained from the Manufacturing Energy Consumption Survey (MECS) 1998 by the four regions into which manufacturing data are traditionally categorized: Northeast, Midwest, South, and West, as shown in Figure 6 (Energy Information Administration 2001a). For the electricity consumption estimate, a value for each manufacturing region is used for each of the Census Divisions that falls within that manufacturing region. The population of industrial-sector workers by establishment was obtained from the U.S. Census Bureau's 1997 Economic Census publication by state and aggregated into the Census Divisions (U.S. Census Bureau 2001). The same outage durations used in the residential and commercial sectors were used in the industrial sector.

\subsubsection{Accounting for Time of Day, Week, and Season When Reliability Events Occur}

In order to accommodate the distinction of time of day, day of week, and season already incorporated in the Tobit regression equations developed by PRS, we needed to derive a method for allocating these different time slices in the year. This section details our approach for weighting the cost per outage per customer by time of day, day of the week, and season.

For our analysis, the morning, night, weekend, and winter parameters shown in Table 7 were weighted to account for the seasons, time of day, and the number of weekdays and weekends. Consistent with what is reported in utility customer surveys, the regression only considers two seasons, summer and winter, so 4,380 hours are binned to each of these seasons, essentially dividing all 8,760 hours of the year into either the summer or winter and excluding spring and fall. The number of weekdays and weekend days were determined assuming the distribution for each month shown in Table 8, which is taken from an Energy Information Administration (EIA) National Energy Modeling System (NEMS) input file. ${ }^{17}$ The number of weekdays amount to 69

\footnotetext{
16 The three-year average median is the sum of three inflation-adjusted-single-year medians divided by three.

17 The proportion of weekdays and weekend days in the year is taken from a DOE/EIA National Energy Modeling System input file. NEMS is a large energy-economy model used to produce the Annual Energy Outlook (AEO). The AEO2003 version of this file used to derive the breakdown is called ldsmcal.txt.
} 
percent of all hours of the year and the number of weekend days account for the remaining 31 percent.

Table 8. Distribution of Weekday and Weekend Days

\begin{tabular}{|l|c|c|}
\hline \multicolumn{1}{|c|}{ Month } & Weekday & Weekend \\
\hline January & 22 & 9 \\
February & 19 & 9 \\
March & 22 & 9 \\
April & 21 & 9 \\
May & 22 & 9 \\
June & 21 & 9 \\
July & 21 & 10 \\
August & 23 & 8 \\
September & 19 & 11 \\
October & 22 & 9 \\
November & 20 & 10 \\
December & 20 & 11 \\
\hline Percent of Year & $\mathbf{6 9 \%}$ & $\mathbf{3 1 \%}$ \\
\hline
\end{tabular}

source: National Energy Modeling System (NEMS) input calendar file (Idsmcal.txt)

With respect to time of day, the morning and afternoon are assumed to contribute six hours each with the night consuming the remaining 12 hours of each day. As a result of this breakdown, a total of 12 different time periods are used to make up all hours of the year as shown in Table 9. Four of the 16 possible permutations of these four parameters were ignored to account for the illogical scenario when an outage occurs during the morning and at night (i.e., morning equal to one and night equal to one). The number of hours assumed for each time period is also shown in the table.

Table 9. Tobit Regression Season, Time of Day, and Day Type Parameter Combinations

\begin{tabular}{|c|cccc|l|c|}
\hline & morning & night & weekend & winter & \multicolumn{1}{|c|}{ Description } & Hours of the Year \\
\hline 1 & 1 & 0 & 0 & 0 & summer, weekday, morning & 756 \\
2 & 0 & 0 & 0 & 0 & summer, weekday, afternoon & 756 \\
3 & 0 & 1 & 0 & 0 & summer, weekday, night & 1,512 \\
4 & 1 & 0 & 1 & 0 & summer, weekend, morning & 339 \\
5 & 0 & 0 & 1 & 0 & summer, weekend, afternoon & 339 \\
6 & 0 & 1 & 1 & 0 & summer, weekend, night & 678 \\
7 & 1 & 0 & 0 & 1 & winter, weekday, morning & 756 \\
8 & 0 & 0 & 0 & 1 & winter, weekday, afternoon & 756 \\
9 & 0 & 1 & 0 & 1 & winter, weekday, night & 1,512 \\
10 & 1 & 0 & 1 & 1 & winter, weekend, morning & 339 \\
11 & 0 & 0 & 1 & 1 & winter, weekend, afternoon & 339 \\
12 & 0 & 1 & 1 & 1 & winter, weekend, night & 678 \\
\hline
\end{tabular}

These assumptions help simplify the allocation of each parameter when calculating a weighted average for the initial estimate cost per outage. The allocation of these twelve time slices in the year determines the weighting that each of the costs per outage per customer experiences throughout the year. 


\subsubsection{Summary of Reliability Event Costs}

Table 10 shows the costs per outage per customer used in the Tobit regression equation to calculate the total cost of power interruptions to U.S. electricity customers. The cost data are classified by customer class (residential, commercial, industrial) and outage duration for the U.S. The costs per outage per customer for individual regions are presented later in this report as part of our sensitivity analysis. Our initial estimate uses the U.S. estimated cost per outage per customer. This table represents the costs for momentary interruptions (i.e. " 0 sec"), 1-hour outages, and the length of outage calculated from our trimmed means of SAIDI and SAIFI (i.e., "Sustained Interruption".) Both the " 0 sec" and "Sustained Interruption" costs are used to derive our initial estimate with the 1-hour cost used later in our sensitivity analysis. It is shown here to indicate the costs associated with this commonly reported outage length. The sustained interruption cost-per-outage-per-customer assumes the trimmed mean outage duration of 106 minutes presented in Section 4.2.

Table 10. Tobit Regression Estimated Cost-per-Outage-per-Customer for the U.S. ${ }^{1}$

\begin{tabular}{|rrrr|}
\hline Duration & Residential & Commercial & Industrial \\
0 sec & $\$ 2.18$ & $\$ 605$ & $\$ 1,893$ \\
Sustained Interruption & $\$ 2.70$ & $\$ 886$ & $\$ 3,253$ \\
\hline
\end{tabular}

${ }^{1}$ Costs shown in U.S. 2002 CPI-weighted dollars

\subsection{Vulnerability of Customers to Reliability Events}

This analysis does not explicitly consider the vulnerability of customers to reliability events. As mentioned earlier in this report, data on customer investments and other efforts to reduce their vulnerability to reliability events are difficult to find. Some data on the sales of back-up generators are known to exist. However, additional research is needed to translate these and related data into a vulnerability index that can be used to adjust the findings presented in this report.

\subsection{LBNL Base-Case Estimate of the Economic Cost of Power Interruptions}

We find that, based on publicly available data and subject to the limitations discussed in this section, the economic cost of power interruptions to U.S. electricity consumers is $\$ 79$ billion annually.

Figure 7 shows how these costs are borne by the three customer classes. The commercial sector accounts for more than 70 percent ( $\$ 57$ billion) of the $\$ 79$ billion estimated combined total cost of power interruptions for all sectors. The commercial sector's large share of these costs is a result of the high costs per outage per customer (shown in Table 10) and the large population of commercial customers. The industrial sector represents nearly 26 percent of the total cost, and the residential sector accounts for less than 2 percent of the total. 


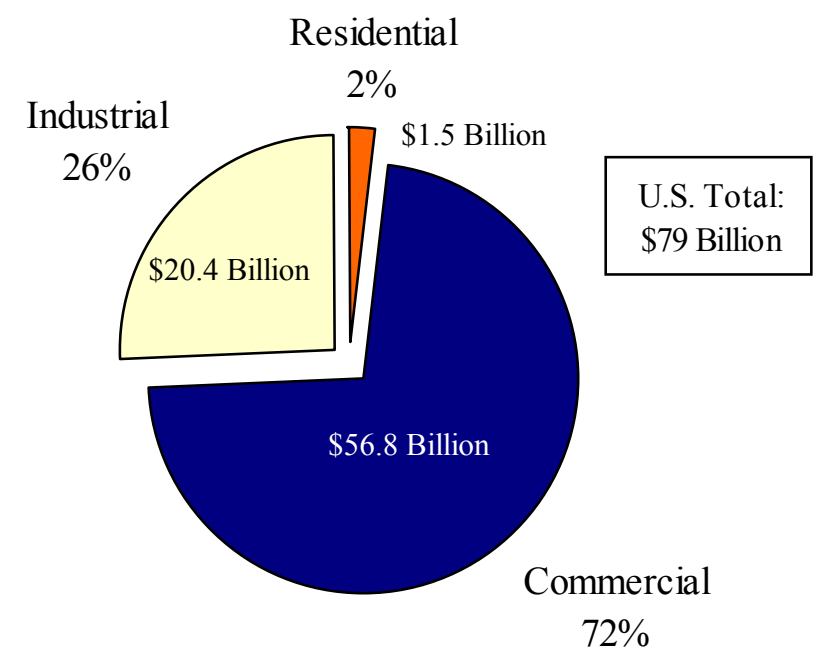

Note: Costs are shown in U.S. 2002-CPI-weighted dollars

Figure 7. LBNL Base-Case Estimate of the Cost of Power Interruptions by Customer Class

Although industrial-sector per-outage-per-customer costs are significantly higher than commercial- and residential-sector costs, the industrial sector's smaller population, 1.6 million customers compared to 14.9 million in the commercial sector, leads to the lower overall estimated cost in this sector. Commercial sector per-outage-per-customer costs are roughly one order of magnitude lower than those for the industrial sector. The 114.3 million residential customers represent by far the largest population of customers in the three sectors, but the costs per outage per customer are two to three orders of magnitude lower than commercial-sector costs, so, despite its large customer population, the contribution from the residential to the total is small.

Figure 8 shows that momentary outages account for two-thirds of the overall cost to the U.S. That is, the 4.3 momentary outages cost the U.S. over $\$ 50$ billion each year, while the 1.2 sustained outages totaling 106 minutes account for the remaining portion of the $\$ 79$ billion total.

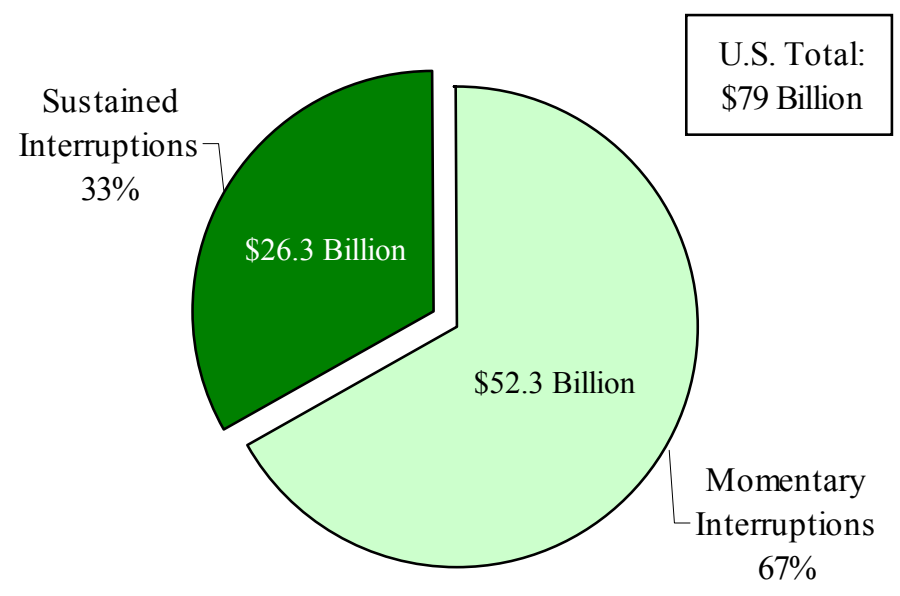

Figure 8. LBNL Base-Case Estimate of the Cost of Power Interruptions by Type of Interruption 
Figure 9 presents the initial estimate by region and customer class to identify any regional variability. The South Atlantic region accounts for the largest contribution, $\$ 14.7$ billion, or nearly 19 percent of the total cost for the U.S. The Pacific region accounts for the smallest of all the regions' costs, only $\$ 2.8$ billion or 3.6 percent of the total.

Figure 9 also compares our regional estimates to the population of commercial and industrial customers in each region to determine how well correlated the regional estimates are to population density. ${ }^{18}$ The differences in the total costs by region appear to correspond largely to these regional population differences. In the South Atlantic region, the higher total cost is clearly linked to the large population. The lowest total costs are seen in the Pacific and New England regions where the customer populations are the smallest.

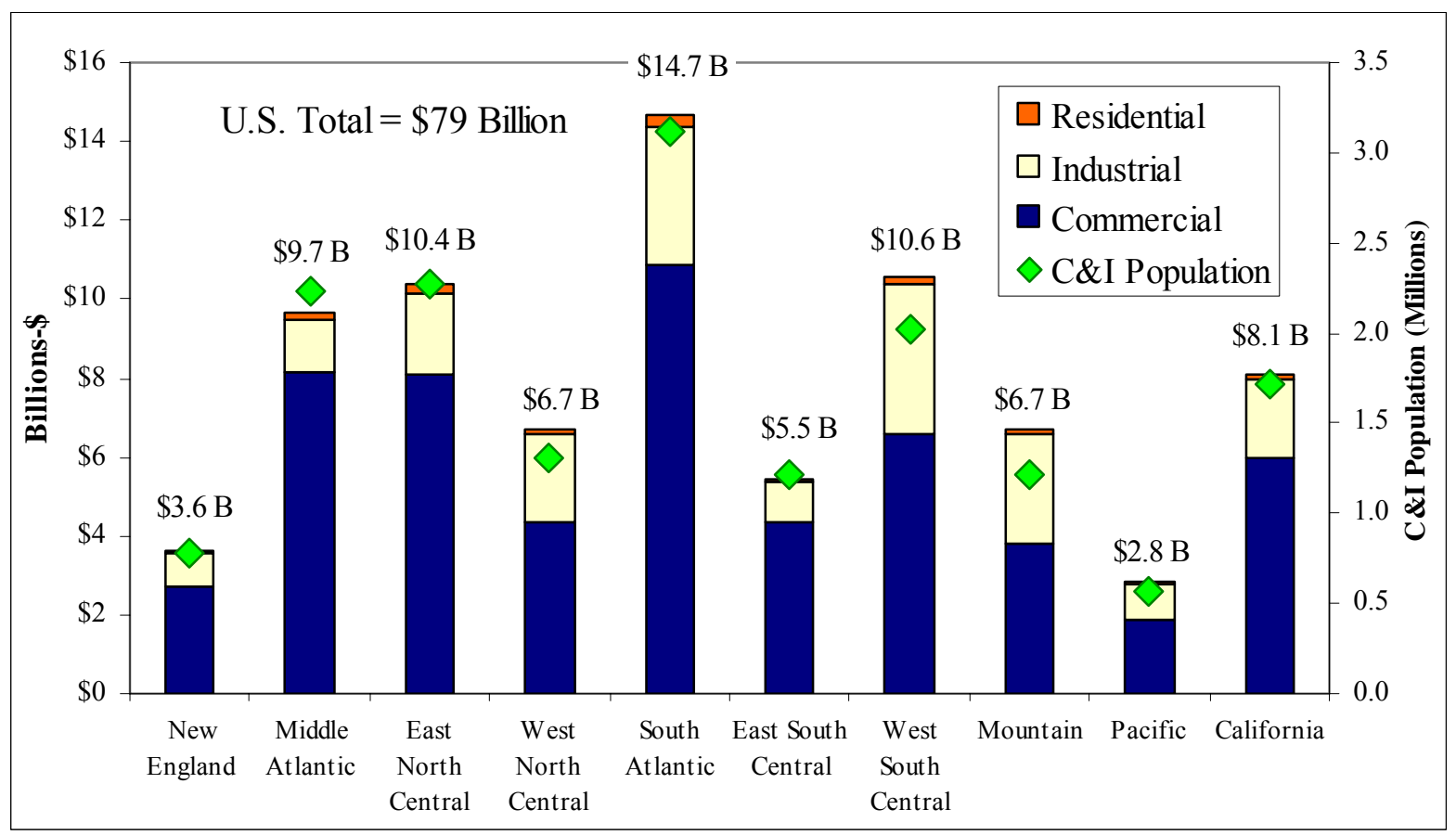

Note: Costs are shown in U.S. 2002-CPI-weighted dollars

Figure 9. LBNL Base-Case Estimate of the Cost of Power Interruptions by Region and Customer Class with C\&I Population

Our findings point to a number of key drivers underlying the national cost of power interruptions:

- The majority of outage costs are borne by the commercial and industrial sectors, and not the residential sector;

- Although there are important variations in the composition of customers types within each region, the total cost of reliability events by region tend to correlate roughly with the numbers of commercial and industrial customers in each region;

\footnotetext{
18 The residential sector population is not included because it is such a large share of the total population, yet provides little overall impact on the cost of power interruptions to the U.S.
} 
- Costs tend to be driven by the frequency rather than the duration of reliability events; and - Momentary power interruptions, which are more frequent, have a stronger impact on the total cost of interruptions than sustained interruptions, which are less frequent.

These findings also point to the underlying assumptions (i.e., customer definitions/populations, outage characteristics, and outage costs) that likely have the greatest influence on our estimate. The next section explores the sensitivities associated with these assumptions to better understand the uncertainties inherent in these assumptions and the impact they have on the total cost of power interruptions. 



\section{Using Sensitivity Analysis to Explore the Uncertainty in the LBNL Estimate}

This section uses the framework developed in Section 2 to explore uncertainties in the LBNL estimate - now called the LBNL Base-case estimate - in three stages. First, we discuss some of the uncertainties associated with the customer class definitions. Second, we explore uncertainties that stem directly from the data we assembled on the duration and frequency of power interruptions. Third, we examine the customer damage functions developed in the PRS study to explore uncertainties regarding the cost of reliability events.

Table 11 summarizes some of the key uncertainties in our estimate and indicates the sub-sections where we examine them in more detail.

Table 11. Key Uncertainties in the Assumptions Used in the LBNL Base-Case Estimate of the Cost of Power Interruptions

\begin{tabular}{|c|l|}
\hline Customers & $\begin{array}{c}\text { Key Uncertainties } \\
\text { Customer classes defined by EIA (residential, commercial, industrial) are not } \\
\text { consistent with customer revenue classes used by utilities (residential, small and } \\
\text { medium CI\&, and large C\&I) - Section 5.1 }\end{array}$ \\
\hline $\begin{array}{c}\text { Duration and } \\
\text { Reliability } \\
\text { Events }\end{array}$ & $\begin{array}{l}\text { SAIDI, SAIFI, and MAIFI are not collected consistently and are often collected } \\
\text { using inconsistent definitions. SAIDI and SAIFI data sometimes exclude major } \\
\text { events (such as those caused be large storms). SAIFI sometimes include events } \\
\text { classified under the definition of MAIFI }\end{array}$ \\
SAIDI, SAIFI, and MAIFI exhibit year to year variability - Section 5.2 \\
$\begin{array}{l}\text { SAIDI, SAIFI, and MAIFI data are reported for an entire population, not by } \\
\text { customer class - Section 5.2 } \\
\text { SAIDI, SAIFI, and MAIFI do not distinguish the time when events occur - } \\
\text { Section 5.3 } \\
\text { SAIDI, SAIFI, and MAIFI data are not readily available in the public domain } \\
\text { Information on power quality events suffer from all of the above limitations to a } \\
\text { degree even greater than SAIDI, SAIFI, or MAIFI. Power quality is not } \\
\text { included in our analysis. }\end{array}$ \\
\hline
\end{tabular}




\begin{tabular}{|c|l|}
\hline $\begin{array}{c}\text { Cost of } \\
\text { Reliability } \\
\text { Events }\end{array}$ & $\begin{array}{l}\text { Customer damage functions were estimated by consolidating a large number of } \\
\text { independent utility outage cost surveys. While survey methods were similar, } \\
\text { they were not identical. Changes in customer costs since the time of the original } \\
\text { surveys have not been examined - Section 5.3 }\end{array}$ \\
& $\begin{array}{l}\text { Utility surveys are designed to capture individual customer experiences with } \\
\text { reliability events, but not infrastructure costs associated with widespread major } \\
\text { outages (e.g., Northeast blackout on August 14-15, 2003) }\end{array}$ \\
\hline $\begin{array}{c}\text { Vulnerability } \\
\text { to Reliability } \\
\text { Events }\end{array}$ & $\begin{array}{l}\text { Comprehensive information on customer investments in reliability enhancing } \\
\text { technologies (such as back-up generation) is not available. }\end{array}$ \\
\hline
\end{tabular}

We used sensitivity analysis to vary the input parameters used in our calculation (in this case, the calculation of the cost of power interruptions) over a reasonable range and observed the resulting change in the result (in this case, power interruption cost). In other words, this process helps determine the sensitivity of the result to changes in parameters. Sensitivity analysis expresses the degree of uncertainty associated with the input parameters as well as the variability in the resulting power interruption cost estimate.

\subsection{Uncertainty in Customer Class Data}

One source of uncertainty associated with our initial cost estimate comes from an assumption that was necessary to reconcile the difference in customer classifications in the sources that we used for cost and population data. Customer population data were reported as "commercial" or "industrial," but outage cost data were reported for two different categories: "small-medium C\&I customers" and "large C\&I customers" (which correspond to utility rate-structure categories). We did not have information that would allow us to consistently re-assign customers classified as small-medium C\&I and large C\&I to the commercial and industrial population categories. Therefore, we made the simple assumption of mapping the small-medium C\&I category to the commercial-sector population and the large $\mathrm{C} \& \mathrm{I}$ category to the industrial-sector population. This simple assumption is the easiest and perhaps most defensible means of making the data conform to one classification system.

A 1990 EIA report notes that, "there is such a discrepancy in how the C\&I are classified" that coming up with a defensible way to partition the small-medium and large C\&I outage-cost categories into commercial and industrial population sectors is challenging. A senior editor at Energy Daily News notes that,

In 1978, Southern California Gas had 8,000 customers they classified as industrial. Following a reclassification that was designed to have their classification conform to the standard industrial classification (SIC) codes, the number of industrial customers increased to 30,000 (Energy Information Administration 1990). ${ }^{19}$

${ }^{19}$ Data quoted in a 1984 letter from Paul Schaffer, Senior Editor for Statistics, Energy Daily News, to Lynda Carlson, Director of the Energy End Use Division of EIA. 
The reclassification described by the editor suggests that there may be significant error in classifications in existing C\&I data banks, so it seems unlikely that our mapping of smallmedium C\&I data to commercial and large C\&I to industrial would significantly affect any preexisting classification errors. In brief, it appears that the C\&I categories are inconsistently defined by the data sources that use them.

\subsection{Uncertainty in Reliability Event Data}

As reported in Table 11, there are many sources of uncertainty associated with currently available information on reliability events. We explored three sources of uncertainty associated with the reliability event data:

- Considering year-to-year variability, as well as the effect of missing data, by assuming plus/minus one standard deviation for the SAIDI, SAIFI, and MAIFI assumptions;

- Exploring the regional variations in the reliability event data; and

- Assuming a different duration and frequency of outages for different classes of customers

These explorations also allow us to develop intuition regarding the likely magnitude of other sources of uncertainty in the initial estimate that we could not examine directly in our sensitivity analysis. Figure 10 summarizes our findings from this set of sensitivity cases.

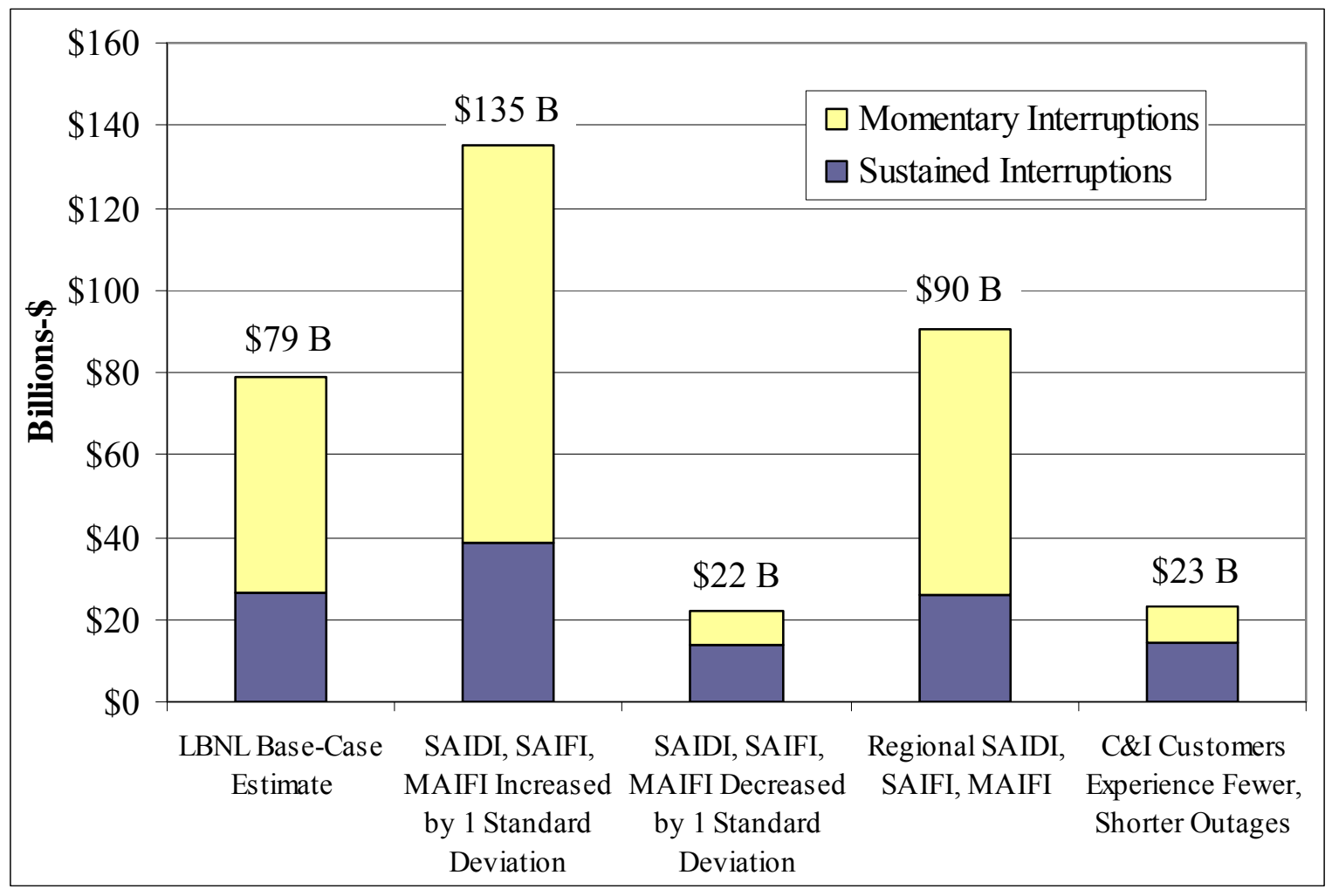

Figure 10. Summary of U.S. Cost of Power Interruption Reliability Event Sensitivity Cases 


\subsubsection{Year-to-Year Variation in Reliability Events}

As a first sensitivity case, we explored the variability in the cost of power interruption estimate by attempting to capture potential year-to-year fluctuations in the reliability event data. In addition, this sensitivity also provides insight into how additional information on reliability events might affect our findings. To examine these issues, we assumed an increase and a decrease of one standard deviation ${ }^{20}$ about our SAIDI, SAIFI, and MAIFI trimmed means.

Referring back to Table 5, this sensitivity assumes the SAIDI fluctuates plus/minus 54 minutes from its mean value of 106 minutes, the SAIFI fluctuates by 0.5 from a mean of 1.2 , and MAIFI varies plus/minus 3.6 from a mean of 4.3. We performed two sensitivity cases to capture this year-to-year variability.

Figure 10 shows the results of these two sensitivity cases. For the plus one standard deviation case, where SAIDI, SAIFI, and MAIFI are 160 minutes, 1.7, and 7.9, respectively, the cost of power interruptions is estimated to be $\$ 135$ billion. This is 70 percent higher than the LBNL base-case estimate of $\$ 79$ billion. With the greater variability associated with the MAIFI data, the additional 3.6 momentary outages in this case account for a large portion of the increase over the initial base-case estimate. For the minus one standard deviation case, we assume SAIDI, SAIFI, and MAIFI are 52 minutes, 0.7 , and 0.7 , respectively. In this scenario of less frequent and shorter duration outages, the overall cost is only $\$ 22$ billion, over $\$ 57$ billion lower than our base-case estimate. Thus, by considering the year-to-year variability of the reliability event data, the cost of power interruptions to U.S. electricity customers could vary considerably from $\$ 22$ billion up to $\$ 135$ billion.

\subsubsection{Regional Variation in Reliability Events}

Although our initial estimate assumed a uniform set of SAIDI, SAIFI, and MAIFI values across all regions, we also experimented with how much different the overall estimate would be if we considered varying the reliability index values for each region. Using the data we collected through our on-line search, we calculated trimmed means for each region as shown in Table 12. This table indicates that there are sometimes large differences from region to region in the duration and frequency of power interruptions. For regions where data could not be found or where the number of data points was less than five, we used the same U.S. average trimmed mean from our initial estimate.

\footnotetext{
${ }^{20}$ Plus or minus one standard deviation means that there is a $67 \%$ chance that the true value would fall between the stated range,
} assuming the cost is normally distributed. 
Table 12. Regional Variation in Collected Reliability Event Data

\begin{tabular}{|c|l|c|c|c|}
\hline Region \# & \multicolumn{1}{|c|}{ Region Name } & SAIDI & SAIFI & MAIFI \\
\hline 1 & New England & 131 & 1.1 & N/A \\
2 & Middle Atlantic & 115 & 1.0 & 9.5 \\
3 & East North Central & N/A & N/A & N/A \\
4 & West North Central & 63 & 0.8 & 11.2 \\
5 & South Atlantic & N/A & N/A & N/A \\
6 & East South Central & N/A & N/A & N/A \\
7 & West South Central & 95 & 1.3 & N/A \\
8 & Mountain & 92 & 1.1 & 3.5 \\
9 & Pacific & 105 & 1.2 & 3.2 \\
10 & California & 138 & 1.3 & 2.3 \\
U.S. & U.S. & 106 & 1.2 & 4.3 \\
\hline
\end{tabular}

Table 13 shows the momentary and sustained per-outage per-customer costs used in this sensitivity case for each region. In general, the per-outage cost does not vary considerably across regions.

Table 13. Tobit Regression Estimated Cost-per-Outage-per-Customer by Region ${ }^{1}$

\begin{tabular}{|c|c|c|c|c|}
\hline \multicolumn{5}{|c|}{ AVERAGE COST PER EVENT BY CUSTOMER CLASS, REGION, AND DURATION OF OUTAGE } \\
\hline Region & Duration & Residential & Commercial & Industrial \\
\hline \multirow{2}{*}{ New England (1) } & $0 \mathrm{sec}$ & $\$ 1.75$ & $\$ 602$ & $\$ 1,885$ \\
\hline & Sustained Outage & $\$ 2.64$ & $\$ 1,256$ & $\$ 5,335$ \\
\hline \multirow{2}{*}{ Middle Atlantic (2) } & $0 \mathrm{sec}$ & $\$ 1.76$ & $\$ 676$ & $\$ 1,880$ \\
\hline & Sustained Outage & $\$ 2.59$ & $\$ 1,370$ & $\$ 5,020$ \\
\hline \multirow{2}{*}{ East North Central (3) } & $0 \mathrm{sec}$ & $\$ 1.77$ & $\$ 567$ & $\$ 1,904$ \\
\hline & Sustained Outage & $\$ 2.43$ & $\$ 995$ & $\$ 4,252$ \\
\hline \multirow{2}{*}{ West North Central (4) } & $0 \mathrm{sec}$ & $\$ 1.79$ & $\$ 574$ & $\$ 1,901$ \\
\hline & Sustained Outage & $\$ 2.36$ & $\$ 940$ & $\$ 3,838$ \\
\hline \multirow{2}{*}{ South Atlantic (5) } & $0 \mathrm{sec}$ & $\$ 2.23$ & $\$ 655$ & $\$ 1,901$ \\
\hline & Sustained Outage & $\$ 3.05$ & $\$ 1,164$ & $\$ 4,244$ \\
\hline \multirow{2}{*}{ East South Central (6) } & $0 \mathrm{sec}$ & $\$ 2.24$ & $\$ 602$ & $\$ 1,923$ \\
\hline & Sustained Outage & $\$ 3.08$ & $\$ 1,062$ & $\$ 4,293$ \\
\hline \multirow{2}{*}{ West South Central (7) } & $0 \mathrm{sec}$ & $\$ 1.82$ & $\$ 574$ & $\$ 1,895$ \\
\hline & Sustained Outage & $\$ 2.35$ & $\$ 907$ & $\$ 3,639$ \\
\hline \multirow{2}{*}{ Mountain (8) } & $0 \mathrm{sec}$ & $\$ 3.00$ & $\$ 583$ & $\$ 1,875$ \\
\hline & Sustained Outage & $\$ 4.01$ & $\$ 981$ & $\$ 3,928$ \\
\hline \multirow{2}{*}{ Pacific (9) } & $0 \mathrm{sec}$ & $\$ 1.80$ & $\$ 604$ & $\$ 1,881$ \\
\hline & Sustained Outage & $\$ 2.45$ & $\$ 1,050$ & $\$ 4,111$ \\
\hline \multirow{2}{*}{ California (10) } & $0 \mathrm{sec}$ & $\$ 1.55$ & $\$ 604$ & $\$ 1,881$ \\
\hline & Sustained Outage & $\$ 2.21$ & $\$ 1,050$ & $\$ 4,111$ \\
\hline \multirow{2}{*}{ U.S. Total } & $0 \mathrm{sec}$ & $\$ 2.18$ & $\$ 605$ & $\$ 1,893$ \\
\hline & Sustained Outage & $\$ 2.99$ & $\$ 1,067$ & $\$ 4,227$ \\
\hline
\end{tabular}

${ }^{1}$ Costs shown in U.S. 2002 CPI-weighted dollars 
Figure 10 shows that the overall cost of power interruptions to U.S. electricity customers is $\$ 90$ billion when considering regional variability in the reliability indices; this is somewhat higher than the LBNL base-case estimate of $\$ 79$ billion. Thus, this exercise suggests that differences in reliability event data by region do not introduce a significant difference in our estimate of the overall U.S. cost of power interruptions. This is not to say that regional differences do not exist or are not important, only that this analysis was not able to identify a significant impact from regional differences in reliability events, based on the data we collected and reviewed.

\subsubsection{Differences by Customer Classes in Reliability Events}

Anecdotal evidence suggests that large customers experience higher levels of reliability compared to small customers. In an attempt to explore this presumption, our third sensitivity case assumes that the commercial and industrial sector customers experience lower values of SAIDI, SAIFI, and MAIFI compared to the residential sector. For this case, we reduced the reliability event data for commercial and industrial customers by one standard deviation (discussed in Section 5.2.1). As well, we also increased the reliability event data for residential customers in order to leave the system totals for SAIDI, SAIFI, and MAIFI unchanged. As a result, the commercial and industrial SAIDI, SAIFI, and MAIFI fall to 52 minutes, 0.7, and 0.7, respectively, while the residential SAIDI, SAIFI, and MAIFI increase to 114 minutes, 1.3, and 4.8 , respectively.

Figure 10 shows the resulting cost of power interruptions to the U.S. for this sensitivity case is $\$ 23$ billion. In other words, by assuming the commercial and industrial sectors experience significantly higher levels of reliability, the overall cost decreases by over $\$ 55$ billion or 70 percent from the LBNL base-case estimate. This reaffirms that our initial estimate likely contains an upward bias due to the uniform assumption of SAIDI, SAIFI, and MAIFI across all three customer classes.

\subsection{Uncertainty in Reliability Event Costs}

The customer damage functions estimated in the PRS study allow us to explore both uncertainties in the data we have relied on as well as key assumptions made by others. In this section, we examine how assumptions in the time of day and week when interruptions occur and how use of unadjusted data from outage cost surveys affect estimates of the cost of power interruptions. Figure 11 summarizes our findings from the series of sensitivity cases of reliability event costs and the following text explains, among other things, why an estimate based on the unadjusted simple means is flawed. 


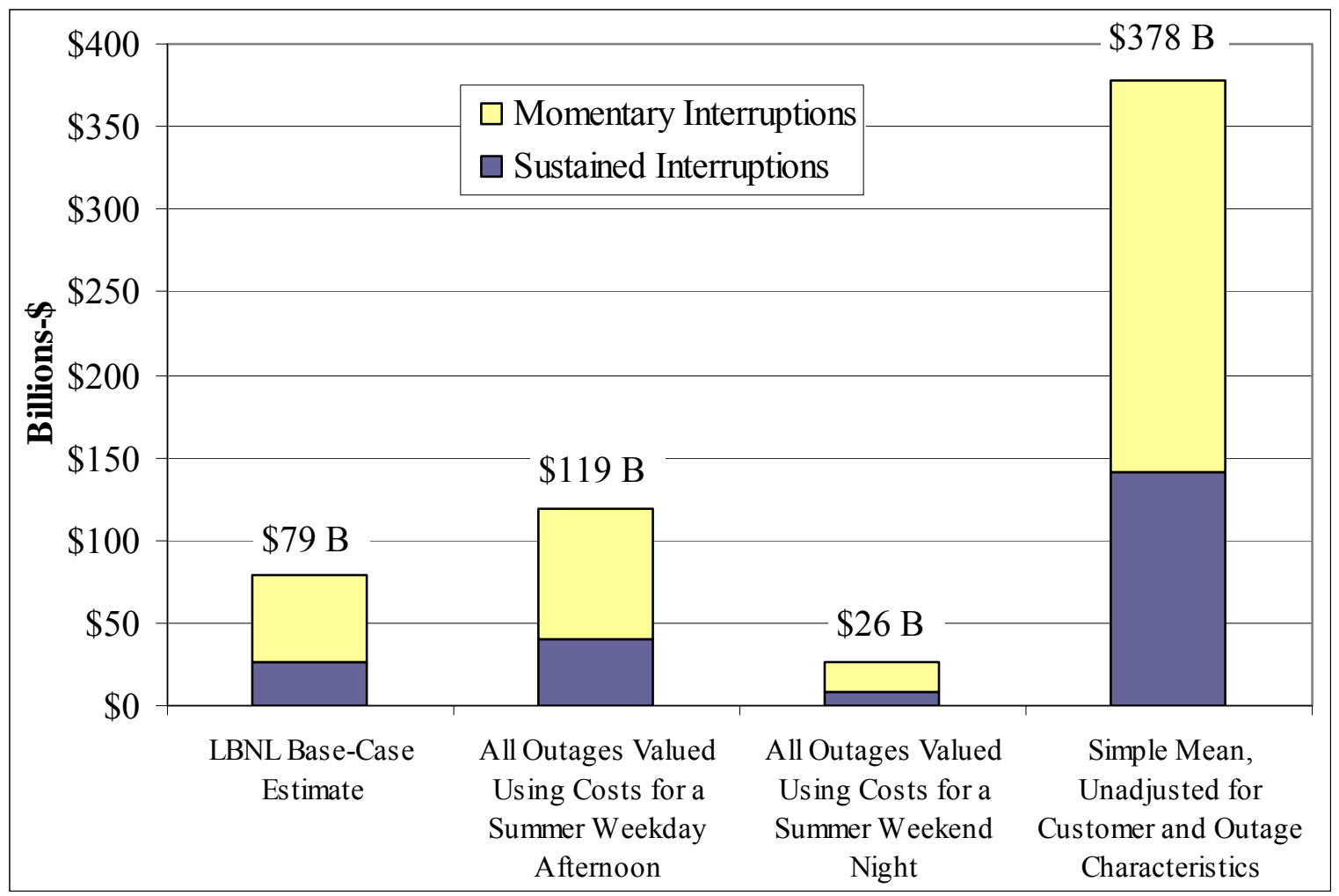

Figure 11. Summary of U.S. Cost of Power Interruption Outage Cost Sensitivity Cases

\subsubsection{Impact of Time when Interruptions Occur on Cost of Reliability Events}

To explore the uncertainty attributed to season, time of day, and day type, we examined two cases assuming the cost of all outages for the year occur during two specific time periods summer weekday afternoon or summer weekend night. Outages on summer weekday afternoons are often assumed to be higher in cost that those that might occur at other times because the weekday afternoon is usually a time of high commercial and industrial activity and during the summer it is also associated with high cooling electricity use. By contrast, outages on summer weekend evenings are thought to be lower in cost since fewer businesses are in operation at this time. Figure 11 compares the total costs by customer class for these two sensitivity scenarios.

It is clear that the uncertainty associated with weighting the outage cost is significant. The costs range from a low of $\$ 26$ billion by assuming all outages are valued as though they occurred on summer weekend nights to a high of $\$ 119$ billion by assuming all outages are valued as though they occurred on summer weekday afternoons.

\subsubsection{Effect of Using Unadjusted Survey Information on Cost of Reliability Events}

We also considered the uncertainty associated with using alternative outage cost data. Our sensitivity explored the influence of using unadjusted survey cost data from the PRS study (Lawton et al. 2003). The unadjusted survey cost data refers to the simple means observed in the data that were assembled from outage-cost surveys before they were adjusted to account for various customer and outage characteristics through the Tobit regression analysis. This exercise 
illustrates the magnitude of uncertainty that can be introduced when using raw survey data. This example shows how simple extrapolations based on these data can lead to serious errors in estimating the cost of power interruptions.

We estimated the cost of power interruptions using simple means from the PRS meta-analysis survey cost data. The 1-hour duration was found to be the most commonly reported across regions and was therefore the one used for this sensitivity case. For this exercise, we assumed a SAIDI of 106 minutes, SAIFI of 1.2, and MAIFI of 4.3, the same values used for our initial estimate. One complication to this sensitivity case was that assuming 1.2 outages lasting a total of 106 minutes meant that each outage was closer to 92 minutes in length, as opposed to 1 hour. For this sensitivity case, we used the 1-hour per outage costs from the PRS study because the unsmoothed data are only reported for selected outage lengths and a 92-minute outage cost could not be obtained from this data set. Therefore our estimate contains uncertainty associated with using the PRS 1-hour outage cost in a scenario that assumes a 92-minute per-outage duration.

The 1-hour costs per outage per customer used for this sensitivity case are shown in Table 14. In general, the per-outage-per-customer cost data in this table are higher than those used for our initial base-case estimate, particularly in the industrial sector where the cost is one order of magnitude higher than those used in our initial estimate (shown in Table 10).

Table 14. PRS Unsmoothed Cost-per-Outage-per-Customer Data

\begin{tabular}{|rrrr|}
\hline Duration & Residential & Commercial & Industrial \\
$0 \mathrm{sec}$ & $\$ 5.84$ & $\$ 1,230$ & $\$ 23,097$ \\
1 hour & $\$ 6.90$ & $\$ 1,859$ & $\$ 59,983$ \\
\hline
\end{tabular}

${ }^{1}$ Costs shown in U.S. 2002 CPI-weighted dollars

Figure 11 shows how much variability can result when using the raw survey data. The estimated cost of power interruptions to U.S. electricity customers is $\$ 378$ billion using the raw survey cost data. ${ }^{21}$ It is interesting to note the shift from commercial-sector dominance when we use the Tobit regressed data to industrial-sector dominance in this sensitivity case. The industrial sector in this case has an estimated \$264 billion power-interruption cost, accounting for 70 percent of the total. The commercial sector accounts for 29 percent, and the residential sector only accounts for 1 percent of the total. This increase is largely a result of the high and more variable outage costs in the industrial sector, which are an order of magnitude greater in this case than the Tobit smoothed survey data.

The purpose of this sensitivity exercise is not to suggest that a power-interruption cost estimate of $\$ 378$ billion is more credible than the LBNL base-case estimate. On the contrary, the PRS meta-analysis points out that using the raw survey cost per outage per customer data is biased toward large industrial customers. This helps explain why the industrial sector cost per outage per customer is so much higher than the Tobit regressed data. This comparison illustrates the significant variability that can be introduced when poor assumptions are made.

\footnotetext{
${ }^{21}$ We also recalculated the initial estimate using a 1-hour outage Tobit regressed cost for ease of comparison and estimated a $\$ 74$ billion overall cost, down slightly from our initial estimate. The cost of power interruptions increases roughly five-fold from $\$ 74$ billion to $\$ 378$ billion when the raw survey data are used in place of the Tobit regressed data.
} 
In summary, the cost of power interruptions is sensitive to changes in the costs per outage per customer. Our sensitivity analysis revealed that day types as well as time of day are significant factors that influence the costs per outage per customer and therefore the estimate of the cost of power interruptions, which can range from \$26 billion up to $\$ 119$ billion based on our analysis. When we compare the smoothed Tobit regression outage costs to the variability exhibited by raw, real-world data in the PRS study, which have been subjected to minimal smoothing, we find that using unsmoothed data results in significantly increased costs, $\$ 378$ billion compared to the $\$ 79$ billion in our initial base-case estimate.

\section{The Reliability Benefits of Energy Storage}

This study does not consider the vulnerability of customers to reliability events. Electric energy storage (storage) is an important way to improve electric service reliability.

At the local/distribution level, storage can absorb, filter out or otherwise compensate for many types of poor power quality. Please see Figure 12. During longer duration power interruptions, storage can carry load for durations of up to several hours or storage can allow for "ride-through" until local or on-site back-up generators can be powered up. After back-up generators begin carrying load, the storage could be used to maintain the quality of power from those generators.

For most electricity storage systems -- especially those with power output less than $10 \mathrm{MW}$-- the leading energy storage medium is the lead-acid battery. Several other notable options also exist or are emerging. ${ }^{22}$ First, there is continuing improvement to lead acid batteries. Other battery chemistries may be alternatives to lead-acid depending, in part, on project scale and how storage will be operated. Some leading candidates are nickel cadmium (NiCad), sodium sulfur, zinc bromine, nickel metal hydride, and lithium ion. Superconducting magnetic energy storage (SMES), flywheel energy storage and "supercapacitors" are three other options. Though not suitable for use at the local, utility distribution level, pumped hydroelectric energy storage (pumped hydro) and compressed air energy storage (CAES) can also provide important support to regional generation and transmission systems.

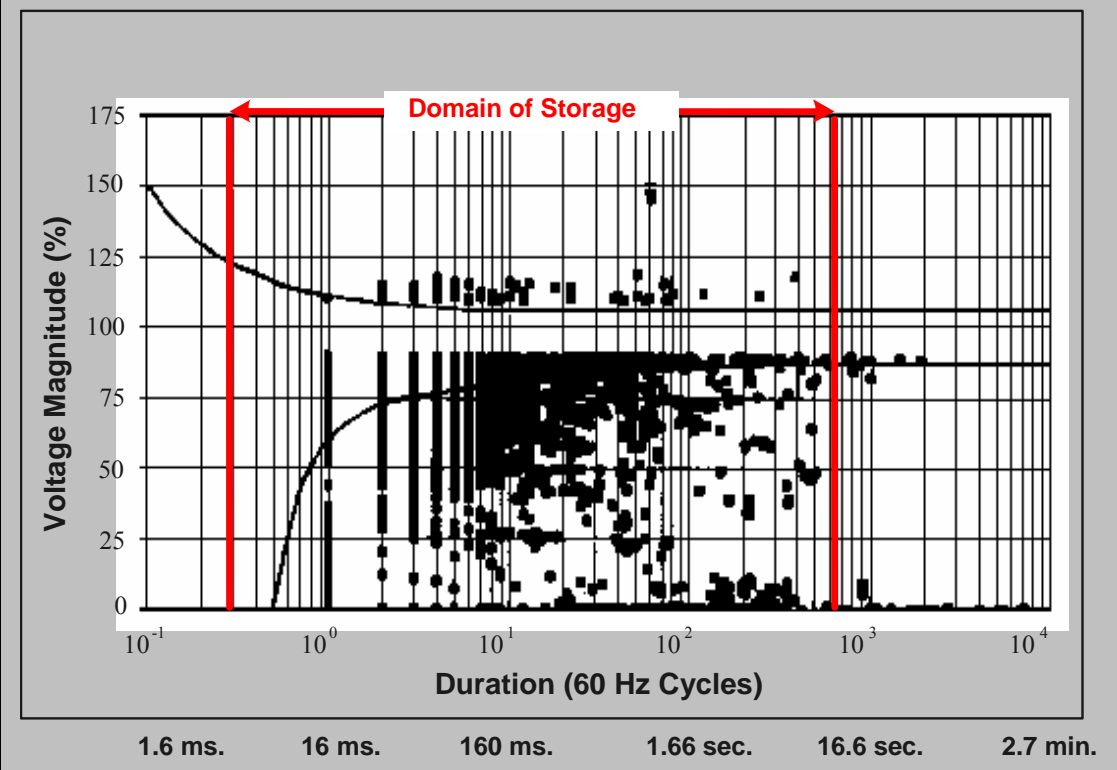

Figure 12. Reliability Events that Could be Addressed by Energy Storage

\footnotetext{
22 Shoenung, Dr. Susan M., Hassenzahl, William M. Long-versus Short-Term Energy Storage Technologies Analysis, A LifeCycle Cost Study. Sandia National Laboratories. SAND2003-2783, August 2003.
} 
Based on an analysis undertaken for the California Energy Commission's Public Interest Energy Research (PIER) Program, economic market potential for storage used in California to improve electric service reliability is about 4 to 6 GigaWatts over ten years, and the potential economic benefit statewide over ten years is $\$ 4.3$ Billion. ${ }^{23}$ The data are summarized in Table 15.

Table 15. Benefits and Market Potential, Over Ten Years, for Energy Storage, used in California, to Improve Electric Service Reliability

\begin{tabular}{|c|c|c|c|}
\hline \multirow[b]{2}{*}{ Application } & \multicolumn{3}{|c|}{ Benefits and Market Potential over 10 Years } \\
\hline & $\begin{array}{c}\text { User } \\
\text { Financial } \\
\text { Benefit } \\
\left(\$ / \mathrm{kW}_{\text {storage }}\right)\end{array}$ & $\begin{array}{l}\text { Maximum } \\
\text { Market } \\
\text { Potential } \\
(\mathrm{MW})\end{array}$ & $\begin{array}{c}\text { Statewide } \\
\text { Economic } \\
\text { Benefit } \\
\text { (\$Million) }\end{array}$ \\
\hline End-user Reliability ${ }^{\star}$ & 359 & 4,005 & 1,438 \\
\hline End-user Power Quality & 717 & 4,005 & 2,872 \\
\hline & TOTALS & $8,010^{\star \star}$ & 4,310 \\
\hline
\end{tabular}

*Storage provides protection against effects of service interruptions that last for as little as a few seconds and as long as several hours.

**Presumably some or even many end-users derive both reliability and PQ related financial benefits. If so, then demand for the two applications is not additive.

For generation and transmission systems storage can be an important tool to maintain system stability. "Bulk" storage systems (tens or hundreds of megawatts) interact directly with the generation and transmission system. Theoretically, smaller storage systems located within electric distribution systems and/or at customer sites can be "dispatched" in concert as a power block, to support the generation and transmission system indirectly, by reducing electric demand when instability occurs.

${ }^{23}$ Request for Proposals, for Electric Energy Storage Demonstration Projects in California. Attachment 14. Benefits and Market Analysis. California Energy Commission, Public Interest Energy Research (PIER) Program. RFP \#500-03-501. July 31, 2003.

24 EPRI-DOE Handbook of Energy Storage for Transmission and Distribution Applications. Electric Power Research Institute, Palo Alto California, and the U.S. Department of Energy. EPRI Report \#1001834. December, 2003. 


\section{Summary, Conclusions, and Priorities for Improving Future Estimates}

This study develops a framework to systematically assess existing studies and then with primary data develop a new estimate of the cost of power interruptions in the U.S. whereby the impact of key underlying uncertainties can be explored. In this section, we summarize our work to date, present our initial conclusions, and discuss priorities for future analyses.

Our analysis establishes an end-use framework for systematically comparing and analyzing estimates of the economic cost of power interruptions and power quality to U.S. electricity customers. Our framework uses electric power customer population, reliability event duration and frequency, and cost per outage per customer to determine the total cost of power interruptions. In addition, we assess the uncertainty associated with each of these parameters. The framework allows us to compare previously published estimates by identifying the strengths and weaknesses associated with each component of the estimate. We then use the framework to develop a new estimate of the cost of power interruptions (not including power quality) and explore the uncertainty associated with our customer class data, reliability event data, and outage cost data assumptions.

Our initial (base-case) estimate for the annual cost for power interruptions to U.S. electricity consumers is $\$ 79$ billion. Our analysis of uncertainty suggests that the costs could be as high as $\$ 135$ billion (assuming plus one standard deviation for SAIDI, SAIFI, and MAIFI from our initial estimate) or as low as $\$ 22$ billion (assuming minus one standard deviation for SAIDI, SAIFI, and MAIFI from our initial estimate) based on the particular sets of sensitivity assumptions we employed. Hence, we present these figures not as the final word on the cost of power interruptions but rather to illustrate the range of variability in estimates, which is directly related to the assumptions on which the estimates are based and uncertainty.

We list below our key findings regarding the accuracy of previous estimates of power interruption costs, the drivers of these costs, and the assumptions and uncertainties that have a significant impact on these cost estimates:

- There is a wide range of uncertainty in the accuracy of previous national power interruption cost estimates because they extrapolate from small subsets of customers or single geographic regions to the whole nation or use outages occurring at one particular time of day, week, or year to represent all outages. Other strategies that introduce inaccuracy include using spending as a proxy for costs.

- The majority of outage costs are borne by the commercial and industrial sectors, and not the residential sector. Although there are important variations in the composition of customer types within each region, the total cost of reliability events by region tends to correlate roughly with the number of commercial and industrial customers in each region.

- Costs tend to be driven by the frequency rather than the duration of reliability events. Momentary power interruptions, which are more frequent, have a stronger impact on the total cost of interruptions than sustained interruptions, which are less frequent.

- As noted, costs could be as low as $\$ 22$ billion or as high as $\$ 135$ billion when we consider a reasonable range in the annual duration and frequency of power interruptions, which 
addresses both gaps in the data for certain regions and possible year-to-year variations in reliability.

- Costs could be as low as $\$ 23$ billion when we take into consideration that larger C\&I customers typically experience fewer and shorter interruptions than do residential and smaller C\&I customers (this difference results from the design of many utility distribution systems).

- Costs might be calculated to be as high as $\$ 119$ billion if all reliability events are (incorrectly) assumed, as is typical in many studies, to occur during summer weekday afternoons when power usage and costs are high.

- The choice of per-outage-per-customer cost data used as a basis for estimating powerinterruption costs has a very significant impact on the estimate. Using unadjusted PRS metaanalysis survey cost data with biases toward large industrial customers resulted in an estimate of $\$ 378$ billion, over five times our initial estimate. This assumption severely overestimates costs because it does not correct for the influence of large industrial customers in the original surveys (compared to the actual distribution of industrial customers), yet provides a sense of the degree of variability that can result when simple assumptions like this are used to evaluate the cost of power interruptions.

In view of these findings, we conclude that there are important uncertainties underlying all present analyses of the cost of power interruptions and power quality to U.S. electricity customers. By and large, these uncertainties reflect the fact that, previously, there have been no systematic efforts to assess this quantity. Key sources of uncertainty and, hence, priorities for future improvements fall into two categories; both apply primarily to the commercial and industrial (rather than residential) sectors:

Better information is needed on customer's reliability experiences. Information on customer's reliability experiences is neither systematically collected nor readily available. Utilities collect reliability event information using standard industry definitions, but do so inconsistently. Information on power quality events is rarely collected at all. Reporting is sporadic and not uniform across the U.S. The information that is collected is aggregated over time and across customer classes, which complicates assigning costs to specific events. The PRS study and the individual surveys that underlie it confirm that the costs of power interruptions and power quality depend on the timing and duration of reliability events, as well as on the characteristics of the customers experiencing them.

Better information is needed on the cost of power interruptions to individual customers. Our initial estimate of the cost of power interruptions to the U.S was based on the most comprehensive assessment of existing utility surveys of customer interruption costs currently in existence. Yet, a major source of uncertainty was variability in these costs, which we were able to demonstrate through sensitivity analyses. Similarly, a major source of uncertainty for the Primen study is extrapolation from a surveyed sample intended to represent 17 percent of the total population of nonresidential customers to the remaining 83 percent that was not surveyed.

Decision about how to address electricity interruption issues in the U.S. should be based, among other things, on a rigorous understanding of the costs of power outages, including power quality. This understanding should include a realistic assessment of the uncertainty inherent in all 
estimates of these costs. Efforts to reduce these uncertainties and hence improve the estimates are urgently needed. In view of the large range of plausible estimates and the enormous cost of the private and public decisions that will be based on them, we encourage policy makers, regulators, and industry to work jointly to undertake the modest-cost activities that are needed to improve the information that is available on reliability events and their costs.

Specific areas for improvement include:

- Coordinated, nationwide collection of updated information on the cost of reliability events to customers;

- Consistent definition and tracking of the frequency, duration, timing, and number and type of customers affected by reliability events, including power-quality events by customer class; and

- Collection of information on efforts by customers to reduce their vulnerability to reliability events through investments in technology and other measures. 



\section{References}

Clemmensen, J., J. Bates, and S. Kraft. 1999. The Top 50 Equipment Suppliers and Service Providers. Power Quality Assurance Magazine, (10): 13-25.

Crosby, P. B. 1979. Quality is Free: The Art of Making Quality Certain, MaGraw-Hill.

Douglas, J. 2000. Employee to EPRI. Personal Communication to J. Eto., Lawrence Berkeley National Laboratory, Berkeley CA.

Electric Power Research Institute. 1993. "Estimating the Cost of Power Quality." IEEE Spectrum, 30 (6), 40.

Electric Power Research Institute. 2003. Distribution Reliability Indices Tracking Within the United States. EPRI. TR-1008459. May. Palo Alto CA.

Electrotek Inc. 1996. An Assessment of Distribution System Power Quality; Volumes 1-3. EPRI. TR-106294-V1-3. Palo Alto CA.

Energy Information Administration. 1990. Energy Consumption by End-use Sector: A Comparison of Measures by Consumption and Supply Surveys. EIA/DOE. DOE/EIA0533. May. Washington D.C.

Energy Information Administration. 2001a. 1998 Manufacturers Energy Consumption Survey. EIA/DOE. February. Washington D.C.

Energy Information Administration. 2001b. Electric Sales and Revenue 2001. December. Washington, D.C.

Energy Information Administration. 2002. 1999 Commercial Buildings Energy Consumption Survey - Detailed Tables. EIA/DOE. August. Washington D.C.

Energy Information Administration. 2003a. 2001 Residential Energy Consumption Survey Detailed Tables. EIA/DOE. October. Washington D.C.

Energy Information Administration. 2003b. Electric Sales and Revenue 2001. EIA/DOE. January. Washington D.C.

Eto, J., D. Divan, and W. Brumsickle. 2004. Pilot Evaluation of Electricity-Reliability and Power-Quality Monitoring in California's Silicon Valley with the I-Grid® System. Lawrence Berkeley National Laboratory. LBNL-52740. Berkeley CA.

Eto, J., J. Koomey, B. Lehman, N. Martin, E. Mills, C. Webber, and E. Worrell. 2001. Scoping Study on Trends in the Economic Value of Electricity Reliability to the U.S. Economy. Lawrence Berkeley National Laboratory. LBNL-47911. June. Berkeley CA.

Fialka, J. 2003. Power Industry Sets Campaign to Upgrade Grid. Wall Street Journal, New York, page A3. August 25. 
IEEE. 1995. IEEE Standard 1159-1995, Recommended Practice for Monitoring Power Quality. IEEE. ISBN\# 1-55937-549-3. New York.

IEEE. 1999. Draft Recommended Practice for Utility Interface of Photovoltaic (PV) Systems. IEEE. P929. November 1999. New York. 43.

Koomey, J., C. Calwell, S. Laitner, J. Thornton, R. E. Brown, and J. Eto. 2002. Sorry, Wrong Number: The Use and Misuse of Numerical Facts in Analysis and Media Reporting of Energy Issues. Annual Reviews, Inc., (also LBNL-50499). Palo Alto, CA. In Annual Review of Energy and the Environment 2002. pp. 119-158.

Kueck, J., B. Kirby, P. Overholt, and L. Markel. 2004. Measurement Practices for Reliability and Power Quality, A Toolkit of Reliability Measurement Practices. Oak Ridge National Laboratory. ORNL/TM-2004/91. June. Oak Ridge, TN. 54 pp.

Lawton, L., M. Sullivan, K. Van Liere, and A. Katz. 2003. Characteristics and Trends in a National Study of Consumer Outage Costs. Population Research Systems, LLC. September 8. San Francisco CA.

Mosteller, F., and J. W. Tukey. 1977. Data Analysis and Regression: A Second Course in Statistics, Addison-Wesley Publishing Company, Reading MA.

National Regulatory Research Institute. 2000. The State Public Service Commission Reliability Survey.

Primen. 2001. The Cost of Power Disturbances to Industrial and Digital Economy Companies. Primen. TR-1006274 (Available through EPRI). June 29. Madison WI.

Schieffer, B. 2003. Face the Nation with Bob Schieffer. Washington D.C. August 17.

Sullivan, M., and D. Keane. 1995. Outage Cost Estimation Guidebook. EPRI. EPRI, TR-106082. Palo Alto, CA.

Swaminathan, S., and R. K. Sen. 1998. Review of Power Quality Applications of Energy Storage Systems. Sandia National Laboratories. SAND98-1513. July. Albuquerque NM and Livermore CA.

U.S. Census Bureau. 2001. 1997 Economic Census: Manufacturing Subject Series. U.S. Department of Commerce. June. Washington D.C. page 193.

U.S. Census Bureau. 2002. Money Income in the United States: 2001. U.S. Department of Commerce. September. Washington D.C. page 33.

Warren, C., D. Pearson, and M. Sheehan. 2003. "A Nationwide Survey of Recorded Information Used for Calculating Distribution Reliability Indices." IEEE Trans. on Power Delivery, $18(2)$. 


\section{Appendix A. Listing of SAIDI, SAIFI, and MAIFI Data}

\begin{tabular}{|c|c|c|c|c|c|c|c|c|}
\hline & SAIFI & SAIDI & CAIDI & MAIFI & ASAI & \# customers & region & notes \\
\hline U.S. ESTIMATE (epri report) & 1.1 & 107 & 97.27 & & & & U.S. & \\
\hline BY UTILITY & SAIFI & SAIDI & CAIDI & MAIFI & ASAI & \# customers & region & notes \\
\hline \multicolumn{9}{|l|}{ Colorado Springs Utility } \\
\hline 1996 & 1.29 & 47.82 & 37.078 & & 99.991 & 160,280 & & \\
\hline 1997 & 0.937 & 45.188 & 48.239 & & 99.991 & 164,681 & & \\
\hline 1998 & 0.721 & 38.658 & 53.589 & & 99.993 & 168,626 & & \\
\hline 1999 & 1.039 & 44.986 & 43.282 & & 99.991 & 173,720 & & \\
\hline 2000 & 1.319 & 46.492 & 35.248 & & 99.991 & 177,825 & & \\
\hline \multicolumn{9}{|l|}{ Public Service Co. of NM } \\
\hline 2000 & 0.856 & & & & & & & \\
\hline 2001 & & 64.87 & 83.7 & 3.47 & 99.986 & $1,300,000$ & & excludes major storms \\
\hline \multicolumn{9}{|l|}{ Indianapolis Power \& Light Co. } \\
\hline 1990 & 0.658 & 36.8 & 55.9 & & 99.993 & & & \\
\hline 1991 & 0.543 & 28.9 & 53.2 & & 99.994 & & & \\
\hline 1992 & 0.574 & 47.8 & 83.3 & 16.29 & 99.991 & & & \\
\hline 1993 & 0.723 & 63.8 & 88.1 & 14.00 & 99.988 & & & \\
\hline 1994 & 0.654 & 37.6 & 57.3 & 12.77 & 99.993 & & & \\
\hline 1995 & 0.746 & 55.2 & 73.9 & 11.11 & 99.990 & & & \\
\hline 1996 & 0.752 & 47.4 & 63.1 & 10.67 & 99.991 & & & \\
\hline 1997 & 0.584 & 31.1 & 53.3 & 8.16 & 99.994 & & & \\
\hline 1998 & 1.022 & 81.3 & 79.6 & 13.18 & 99.985 & & & \\
\hline 1999 & 0.696 & 41.3 & 59.4 & 11.09 & 99.992 & & & \\
\hline \multicolumn{9}{|c|}{ City Public Service (San Antonio Texas) } \\
\hline 1998 & 1.13 & 50.52 & 44.71 & & & & & \\
\hline 1999 & 0.919 & 53.16 & 57.85 & & & & & \\
\hline 2000 & 1.162 & 43.68 & 37.59 & & & & & \\
\hline 2001 & 1.527 & 67.44 & 44.17 & & & & & \\
\hline \multicolumn{9}{|l|}{ Georgetown Utility System (Texas) } \\
\hline 2001 & 0.31 & 105 & 197 & & 99.98 & & & \\
\hline \multicolumn{9}{|l|}{ Redding Electric Utility } \\
\hline 5-Year Avg 1998-2002 & 0.45 & 40 & 88.89 & & & & & including major storms \\
\hline 5-Year Avg 1998-2002 & 0.38 & 30 & 78.95 & & & & & excluding major storms \\
\hline \multicolumn{9}{|l|}{ Connecticut Light and Power Co. } \\
\hline 1996 & 2.54 & 893 & 351.57 & & & & & including major storms \\
\hline 1997 & 1.69 & 320 & 189.35 & & & & & \\
\hline 1998 & 1.35 & 205 & 151.85 & & & & & \\
\hline 1999 & 1.77 & 352 & 198.87 & & & & & \\
\hline 2000 & 1.14 & 240 & 210.53 & & & & & \\
\hline 2001 & 1.09 & 171 & 156.88 & & & & & \\
\hline \multicolumn{9}{|l|}{ Connecticut Light and Power Co. } \\
\hline 1996 & 1.16 & 130 & 112.07 & & & & & excluding major storms \\
\hline 1997 & 1.22 & 116 & 95.08 & & & & & \\
\hline 1998 & 1.14 & 129 & 113.16 & & & & & \\
\hline 1999 & 1.02 & 107 & 104.90 & & & & & \\
\hline 2000 & 0.75 & 81 & 108.00 & & & & & \\
\hline 2001 & 0.84 & 102 & 121.43 & & & & & \\
\hline Portland Gas \& Electric (Oregor & & & & & & & & \\
\hline 1998 & 0.8 & 90 & 112.50 & 1.5 & & & \multicolumn{2}{|r|}{ major events eligible for exclusi } \\
\hline 1999 & 0.8 & 84 & 105.00 & 3.35 & & & & \\
\hline 2000 & 0.65 & 63 & 96.92 & 2.7 & & & & \\
\hline 2001 & 0.65 & 66 & 101.54 & 2.2 & & & & \\
\hline 2002 & 0.65 & 72 & 110.77 & 2.25 & & & & \\
\hline \multicolumn{9}{|l|}{ PacifiCorp (Oregon) } \\
\hline 1998 & 1.05 & 90 & 85.71 & 3.25 & & & \multicolumn{2}{|c|}{ major events eligible for exclusi } \\
\hline 1999 & 0.9 & 84 & 93.33 & 5.4 & & & & \\
\hline 2000 & 0.7 & 63 & 90.00 & 5.75 & & & & \\
\hline 2001 & 0.9 & 96 & 106.67 & 4.9 & & & & \\
\hline 2002 & 1.35 & 154.8 & 114.67 & 1.1 & & & & \\
\hline \multicolumn{9}{|l|}{ CLEO Corp. Esco (Louisianna) } \\
\hline 1998 & 1.25 & 105 & 84.00 & & & & & \\
\hline 1999 & 1.39 & 106.8 & 76.83 & & & & & \\
\hline 2000 & 1.41 & 109.2 & 77.45 & & & & & \\
\hline 2001 & 1.82 & 144 & 79.12 & & & & & \\
\hline 2002 & 2.09 & 169.2 & 80.96 & & & & & \\
\hline
\end{tabular}




\begin{tabular}{|c|c|c|c|c|c|c|c|c|}
\hline BY UTILITY & SAIFI & SAIDI & CAIDI & MAIFI & ASAI & \# customers & region & notes \\
\hline \multicolumn{9}{|l|}{ California PUC } \\
\hline 1993 & 1.545 & 159.3 & 103.11 & 1.36 & & & PG\&E & including major events \\
\hline 1994 & 1.4 & 139.2 & 99.43 & 1.46 & & & & \\
\hline 1995 & 2.393 & 536.6 & 224.24 & 1.71 & & & & \\
\hline 1996 & 1.685 & 198.4 & 117.74 & 6.52 & & & & \\
\hline 1997 & 1.562 & 157.3 & 100.70 & 4.37 & & & & \\
\hline 1998 & 1.812 & 245 & 135.21 & 3.49 & & & & \\
\hline 1999 & 1.324 & 145.1 & 109.59 & 2.59 & & & & \\
\hline 2000 & 1.293 & 152.3 & 117.79 & 2.24 & & & & \\
\hline 2001 & 1.43 & 228.6 & 159.86 & 2.21 & & & & \\
\hline 2002 & 1.549 & 343.7 & 221.89 & & & & & \\
\hline \multicolumn{9}{|l|}{ California PUC } \\
\hline 1993 & 1.424 & 136.9 & 96.14 & 1.31 & & & PG\&E & excluding major events \\
\hline 1994 & 1.4 & 139.2 & 99.43 & 1.39 & & & & \\
\hline 1995 & 1.384 & 150.3 & 108.60 & 1.27 & & & & \\
\hline 1996 & 1.632 & 167.1 & 102.39 & 6.3 & & & & \\
\hline 1997 & 1.507 & 148.4 & 98.47 & 4.25 & & & & \\
\hline 1998 & 1.493 & 157.3 & 105.36 & 3.11 & & & & \\
\hline 1999 & 1.321 & 144.8 & 109.61 & 2.58 & & & & \\
\hline 2000 & 1.29 & 151.8 & 117.67 & 2.24 & & & & \\
\hline 2001 & 1.315 & 192.5 & 146.39 & 2.08 & & & & \\
\hline 2002 & 1.046 & 131.6 & 125.81 & & & & & \\
\hline \multicolumn{9}{|c|}{ Chelan County PUD (Washington) } \\
\hline 1991 & 0.31 & 40.95 & 132.10 & & & & & \\
\hline 1992 & 0.51 & 71.97 & 141.12 & & & & & \\
\hline 1993 & 0.44 & 68.97 & 156.75 & & & & & \\
\hline 1994 & 0.39 & 44.49 & 114.08 & & & & & \\
\hline 1995 & 0.42 & 82.12 & 195.52 & & & & & \\
\hline 1996 & 0.57 & 115.71 & 203.00 & & & & & \\
\hline 1997 & 0.2 & 40.69 & 203.45 & & & 37,633 & & \\
\hline \multicolumn{9}{|c|}{ Clark County PUD (Washington) } \\
\hline 1990 & 2.43 & 107.26 & 44.14 & & & & & \\
\hline 1991 & 5.02 & 26.12 & 5.20 & & & & & \\
\hline 1992 & 2.22 & 55.44 & 24.97 & & & & & \\
\hline 1993 & 4.6 & 64.51 & 14.02 & & & & & \\
\hline 1994 & 3.77 & 75.74 & 20.09 & & & & & \\
\hline 1995 & 4.07 & 680.78 & 167.27 & & & & & \\
\hline 1996 & 4.86 & 126.55 & 26.04 & & & & & \\
\hline 1997 & 2.15 & 51.9 & 24.14 & & & 134,400 & & \\
\hline \multicolumn{9}{|c|}{ Cowlitz County PUD (Washington) } \\
\hline 1992 & 0.77 & 116.48 & 151.27 & & & & & \\
\hline 1993 & 1.49 & 161.21 & 108.19 & & & & & \\
\hline 1994 & 1.26 & 160.49 & 127.37 & & & & & \\
\hline 1995 & 1.19 & 147.7 & 124.12 & & & & & \\
\hline 1996 & 3.05 & 267.3 & 87.64 & & & & & \\
\hline 1997 & 1.87 & 201.41 & 107.71 & & & 42,700 & & \\
\hline \multicolumn{9}{|c|}{ Franklin County PUD (Washington) } \\
\hline 1992 & 0.016 & 2.94 & 183.75 & & & & & \\
\hline 1993 & 0.009 & 1.32 & 146.67 & & & & & \\
\hline 1994 & 0.015 & 2.46 & 164.00 & & & & & \\
\hline 1995 & 0.014 & 1.92 & 137.14 & & & & & \\
\hline 1996 & 0.017 & 2.72 & 160.00 & & & & & \\
\hline 1997 & 0.014 & 2.44 & 174.29 & & & 17,680 & & \\
\hline \multicolumn{9}{|c|}{ Grant County PUD \#2 (Washington) } \\
\hline 1993 & 1.55 & 152.43 & 98.34 & & & & & \\
\hline 1994 & 1.24 & 102.33 & 82.52 & & & & & \\
\hline 1995 & 0.79 & 60.92 & 77.11 & & & & & \\
\hline 1996 & 1.05 & 85.02 & 80.97 & & & & & \\
\hline 1997 & 0.83 & 63.73 & 76.78 & & & 38,538 & & \\
\hline \multicolumn{9}{|c|}{ Grays Harbor County PUD (Washington) } \\
\hline 1991 & 1.67 & 183.6 & 109.94 & & & & & \\
\hline 1992 & 2.83 & 477.6 & 168.76 & & & & & \\
\hline 1993 & 1.73 & 581.14 & 335.92 & & & & & \\
\hline 1994 & 3.4 & 558.8 & 164.35 & & & & & \\
\hline 1995 & 2.03 & 174.5 & 85.96 & & & & & \\
\hline 1996 & 1.38 & 160.88 & 116.58 & & & & & \\
\hline 1997 & 2.33 & 268.4 & 115.19 & & & 38,680 & & \\
\hline
\end{tabular}




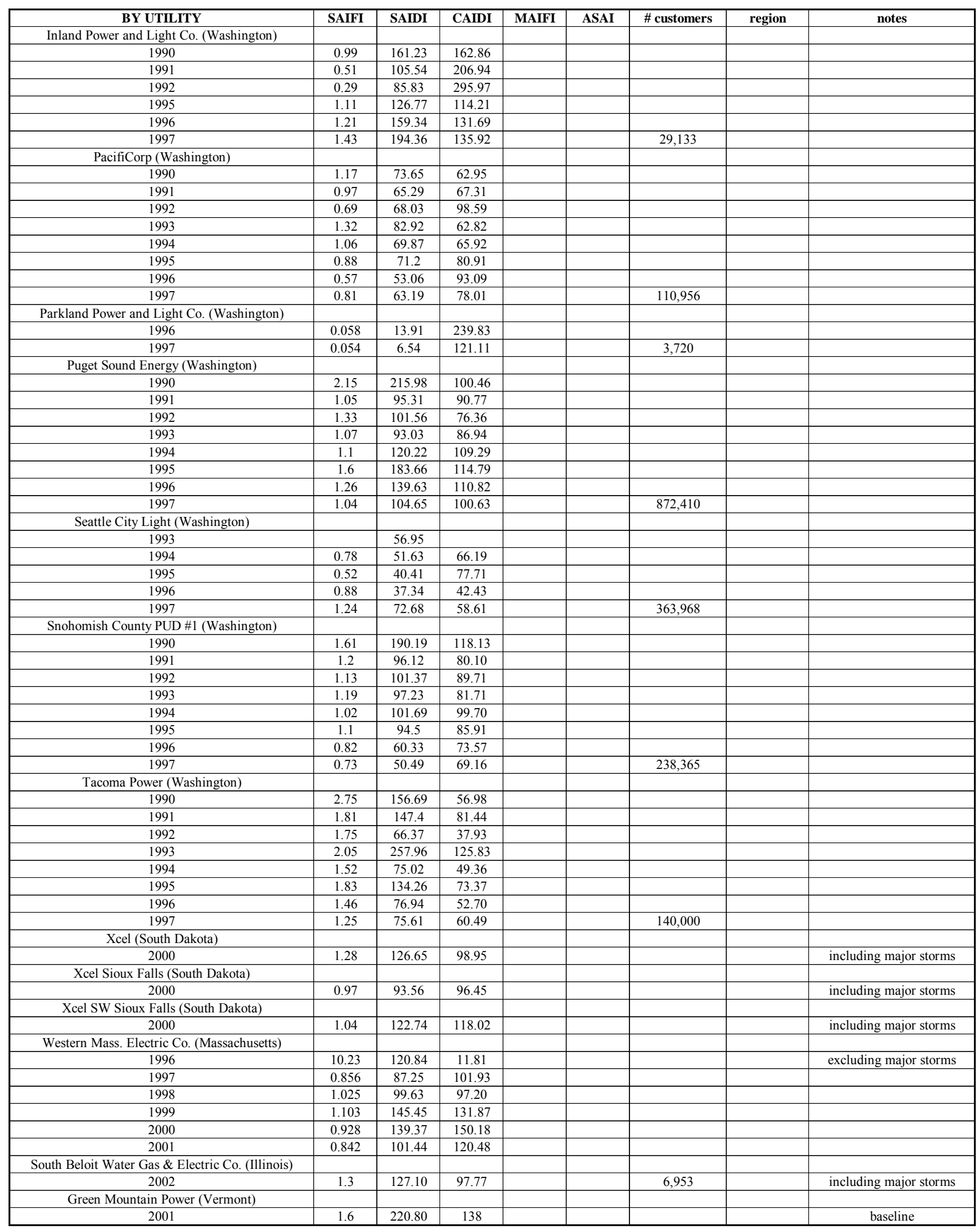




\begin{tabular}{|c|c|c|c|c|c|c|c|c|}
\hline BY UTILITY & SAIFI & SAIDI & CAIDI & MAIFI & ASAI & \# customers & region & notes \\
\hline \multicolumn{9}{|c|}{ Penn. PUC (Pennsylvania) } \\
\hline Allegheny Power & 0.67 & 116 & 173.13 & & & & & current benchmark 2003 \\
\hline Duquesne Light & 1.15 & 123 & 106.96 & & & & & current benchmark 2003 \\
\hline Med-Ed & 0.97 & 113 & 116.49 & & & & & current benchmark 2003 \\
\hline Penelec & 1.07 & 108 & 100.93 & & & & & current benchmark 2003 \\
\hline Penn Power & 1.01 & 95 & 94.06 & & & & & current benchmark 2003 \\
\hline PECO & 1.23 & 138 & 112.20 & & & & & current benchmark 2003 \\
\hline PPL & 0.88 & 113 & 128.41 & & & & & current benchmark 2003 \\
\hline \multicolumn{9}{|c|}{ San Diego Gas \& Electric } \\
\hline 1994 & 0.94 & 69.4 & 73.83 & 0.86 & & & & \\
\hline 1995 & 0.72 & 57.8 & 80.28 & 1.31 & & & & \\
\hline 1996 & 1.04 & 81.9 & 78.75 & 1.53 & & & & \\
\hline 1997 & 0.93 & 89.4 & 96.13 & 1.41 & & & & \\
\hline \multicolumn{9}{|l|}{1998} \\
\hline 1999 & & & & 0.796 & & & & \\
\hline 2000 & & & & 0.755 & & & & \\
\hline 2001 & & & & 0.9 & & & & \\
\hline \multicolumn{9}{|l|}{ Sempra Energy } \\
\hline 2002 & & & & 0.605 & & & & \\
\hline 2003 & & & & 0.85 & & & & \\
\hline \multicolumn{9}{|c|}{ Long Island Power Authority } \\
\hline 1995 & & & & 12.5 & & & & \\
\hline 1996 & & & & 11.2 & & & & \\
\hline 1997 & & & & 8.4 & & & & \\
\hline 1998 & & & & 8.3 & & & & \\
\hline 1999 & & & & 7.2 & & & & \\
\hline \multicolumn{9}{|c|}{ City of Longmont, Colorado } \\
\hline 1997 & 0.50 & 53.50 & 107.00 & 4.70 & & & & \\
\hline 1999 & 0.69 & 38.64 & 56.00 & 4.60 & & & \multicolumn{2}{|c|}{1999 data from Colorado Longm } \\
\hline 2001 & 0.90 & 51.97 & 57.81 & 2.77 & & & & \\
\hline 2002 & 0.64 & 33.44 & 52.33 & 1.82 & & & & \\
\hline 2003 & 0.54 & 23.98 & 44.25 & 0.75 & & & & \\
\hline
\end{tabular}

